Policy Research Working Paper 7009

\begin{abstract}
The pattern of global land use has important implications for the world's food and timber supplies, bioenergy, biodiversity and other eco-system services. However, the productivity of this resource is critically dependent on the world's climate, as well as investments in, and dissemination of improved technology. This creates massive uncertainty about future land use requirements which compound the challenge faced by individual investors and governments seeking to make long term, sometimes irreversible investments in land conversion and land use. This study assesses how uncertainties
\end{abstract}

associated with underlying biophysical processes and technological change in agriculture affect the optimal profile of land use over the next century, taking into account the potential irreversibility in these decisions. A novel dynamic stochastic model of global land use is developed, in which the societal objective function being maximized places value on food production, liquid fuels (including bio-fuels), timber production, and biodiversity. While the uncertainty in food crop yields has anticipated impact, the resulting expansion of crop lands and decline in forest lands is relatively small.

This paper is a product of the Environment and Energy Team, Development Research Group. It is part of a larger effort by the World Bank to provide open access to its research and make a contribution to development policy discussions around the world. Policy Research Working Papers are also posted on the Web at http://econ.worldbank.org. The authors may be contacted at jsteinbuks@worldbank.org.

The Policy Research Working Paper Series disseminates the findings of work in progress to encourage the exchange of ideas about development issues. An objective of the series is to get the findings out quickly, even if the presentations are less than fully polished. The papers carry the names of the authors and should be cited accordingly. The findings, interpretations, and conclusions expressed in this paper are entirely those of the authors. They do not necessarily represent the views of the International Bank for Reconstruction and Development/World Bank and its affliated organizations, or those of the Executive Directors of the World Bank or the governments they represent. 


\title{
The Effect of Climate and Technological Uncertainty in Crop Yields on the Optimal Path of Global Land Use*
}

\author{
Yongyang Cai \\ Jevgenijs Steinbuks \\ Joshua Elliott \\ Thomas W. Hertel
}

JEL: C61, Q15, Q23, Q26, Q40, Q54

Keywords: Climate Change, Crop Yields, Dynamic Stochastic Models, Global Land Use, Uncertainty

Sectors: Agriculture, Climate Change, Forestry, Environment

*Cai: Hoover Institution, Stanford University and Becker Friedman Institute, University of Chicago, yycai@stanford.edu. Steinbuks: Development Research Group, The World Bank, jsteinbuks@worldbank.org. Hertel: Center for Global Trade Analysis, Purdue University, hertel@purdue.edu. Elliott: Computation Institute, University of Chicago, jelliott@ci.uchicago.edu. Acknowledgements: The authors are sincerely grateful to Kenneth Judd for his invaluable contributions that greatly improved this paper. They appreciate financial support from the National Science Foundation, grant 0951576 "DMUU: Center for Robust Decision Making on Climate and Energy Policy" and hardware support of the BlueWaters and Beagle supercomputer projects. 


\section{Introduction}

The allocation of the world's land resources over the course of the next century has become a pressing research question. Continuing population increases, improving, land-intensive diets among the poorest populations in the world, increasing production of biofuels and rapid urbanization in developing countries are all competing for land even as the world looks to land resources to supply more environmental services. The latter include biodiversity and natural lands, as well as forests and grasslands devoted to carbon sequestration. And all of this is taking place in the context of faster than expected climate change which is altering the biophysical environment for land-related activities. This combination of intense competition for land, coupled with highly uncertain future productivities and valuations of environmental services, gives rise to a significant problem of decision-making under uncertainty.

The growing significance of global land use allocation issue was not left unnoticed by the academic community over the recent decade. A large and rapidly expanding body of interdisciplinary research has emerged, focusing on major drivers affecting competition for global land use in the long run. ${ }^{1}$ The economic analysis on this issue has largely revolved around two rather distinct strands of literature.

The first strand of economic literature builds on land based integrated assessment models (IAMs) used to evaluate the costs and benefits of greenhouse gas (GHG) mitigation. These large-scale computational models (see e.g., Paltsev et al., 2005; Bouwman et al., 2006; Wise and Calvin, 2011) have an important advantage of detailed geographic and sectoral (particularly, energy sector) coverage, which allow them to capture a broad range of market mediated responses to changes in demand and supply factors affecting global land use. Because of these attractive features IAMs have been extensively used to analyze the effect of energy and climate policies affecting competition between food and biofuels (Gurgel et al., 2007; Searchinger et al., 2008; Wise et al., 2009), and climate change impacts on yields and available area in agriculture and forestry sectors (Parry et al., 2004; Reilly et al., 2007; Hertel et al., 2010c).

However these models are typically either static or 'backward looking' in their recursive-dynamic structure, and therefore have limited ability to address important intertemporal questions, such as e.g., inter-temporal allocation of GHG emission flows from land-use through abatement policies, efficiency implications of carbon taxes and caps, and endogenous depletion of non-renewable land resources. None of these models explicitly incorporate uncertainty into the determination of the optimal path of global land use. To the extent that uncertainty is dealt with, this is only through sensitivity analysis or alternative scenarios. This ignores the impact of future uncertainty on optimal decision making. In the case of competition between agriculture and forestry, this failure to model uncertainty directly could have large implications for the results given that land use change decisions are typically costly to reverse.

\footnotetext{
${ }^{1}$ For an excellent survey of this literature see Hertel (2011).
} 
The second strand of the economic literature, on the contrary, sacrifices comprehensive sectoral representation for more elaborate treatment of intertemporal issues. This literature typically focuses on a particular land-intensive sector, where intertemporal issues are significant and cannot be ignored. One example of this literature is commercial forestry management in the context of uncertain fire risks and climate mitigation policies (Stavins, 1999; Sohngen and Mendelsohn, 2003; Richards and Stokes, 2004; Sohngen and Mendelsohn, 2007; Daigneault et al., 2010). Another example is natural land conservation decisions under irreversibility from loss of biodiversity and significant option values attached to the future stream of benefits from ecosystem services (Conrad, 1997, 2000; Bulte et al., 2002; Leroux et al., 2009).

In this study, we seek to bridge the gap between these two distinct strands of economic literatures. Specifically, we aim to assess the optimal path of global land use over next century, accounting for both sectoral competition for global land resources and intertemporal decisions under climate and technology uncertainties affecting crop yields and, therefore, also optimal land allocation. While we have no illusions that the world's lands will be optimally allocated in the coming century, this path provides a useful guideline to understanding the impact of uncertain crop yields on a wide range of land use decisions at global scale. To our knowledge, this is the first study that integrates the decision making under uncertainty into a multi-sectoral economic model of global land use.

Our choice of uncertainty focuses on crop yield dynamics over the course of next century. Along with energy prices, regulatory policies, and technological change in food, timber and biofuels industries, this is one of four core uncertainties affecting competition for global land use Steinbuks and Hertel (2013). Quantification of uncertainty in potential crop yields focuses on two most important drivers recognized in agronomic and biophysical literatures (Lobell et al., 2009; Licker et al., 2010; Foley et al., 2011) - the technological progress in agriculture and climate change, and its associated impact on crop yields. Both sources underlying the uncertainty crop yield dynamics are very complex and hard to quantify. The advances of crop technology are very difficult to predict. There is a significant uncertainty about the extent to which one can exploit large and economically significant yield gaps in developing countries. Even less certain is the path of future innovations in plant breeding. Assessing the impact of climate change on agricultural yields is also very complicated task. There is a significant uncertainty in future GHG concentrations and their induced warming along the long run growth path of the global economy. The impacts of changes in temperature and precipitation on plant growth and the productivity of agriculture in different agro-ecological conditions are no more certain.

Our analysis builds on Steinbuks and Hertel (2013), who develop a dynamic, forward-looking global multi-sectoral partial equilibrium model to compare the effects of core known uncertainties on the optimal profile for global land use and land-based GHG emissions over the next century. They find that longterm uncertainty in energy prices dominates the climate impacts and climate policy uncertainties emphasized in prior research on global land use. However, 
the modeling approach of Steinbuks and Hertel (2013) has several important limitations, which we attempt to address in this paper. First, they adopt a very simplistic approach to quantifying uncertainty in crop yields, focusing on rather simplistic representation of climate impacts, and ignoring uncertainty in the evolution of agricultural technology. Second, their model is perfect foresight and assumes risk-neutral agents, and thus ignores the impact of future uncertainty on optimal allocation of global land use.

The model we develop is a long-run dynamic stochastic partial equilibrium framework in which the societal objective function being maximized places value on food production, liquid fuels (including biofuels), timber production and biodiversity. A non-homothetic AIDADS utility function represents model preferences, and, as society becomes wealthier, places greater value on eco-system services, and smaller value on additional consumption of food, energy and timber products. The forestry sector is characterized by multiple forest vintages, which add considerable computational complexity in the context of this dynamic stochastic analysis. To meet the significant computational challenge of this high-dimensional problem, we use recent state of art methods in parallel dynamic programming and implement them on a supercomputer.

To quantify the uncertainty in climate impacts on agricultural yields we follow the methodological approach of Rosenzweig et al. (2014). Our estimates are based on the results from Decision Support System for Agrotechnology Transfer (DSSAT) crop simulation model for four major crops, run globally on a 0.5 degree grid and weighted by agricultural output under different GHG forcing scenarios using outputs from five different global climate models. Our estimates of uncertainty in agricultural technology is based on recent agro-economic and biophysical studies assessing the potential for closing yield gaps and advances in plant breeding.

The model is solved over the period 2005-2204, with an emphasis on the first century. The model baseline accurately reflects developments in global land use over the 10 years that have already transpired, while also incorporating projections of population, income and demand growth from a variety of international agencies. We show the results of the perfect foresight model, whereby climate and technology shocks to crop yields are absent and compare and contrast them with the results of the dynamic stochastic model, where the uncertainty in crop yields is brought to the model's optimization stage. Our model baseline results suggest that, in the near term decades, there is a significant expansion in the area dedicated to food crops due to rapid population growth and increasing demand for food at subsistence level. The expansion in cropland is largely associated with a accelerated loss of unmanaged natural forests, whereas managed forest lands are little changed. In the second half of the coming century slower population growth, and technology improvements in crop yields and food processing result in a smaller demand for crop land. By 2100 cropland area is just 4 percent larger than in 2004. Managed and protected natural forest land areas grow significantly by the end of the century, reflecting rising real incomes, and growing demand for timber products and ecosystem services. The results of the dynamic stochastic analysis are consistent with the expected hypothesis that 
higher crop yields require smaller use of crop land. However, the magnitude of the change in land use around different paths of the stochastic crop technology index is small. The difference between the most optimistic and pessimistic states of the crop technology index is about 30 million hectares, which is about 2 percent of the total crop land in 2004. The uncertainty in crop technology has more profound impact on the consumption of food as well as for the first generation biofuels consumption over the coming century.

\section{Analytical Framework}

This section develops a dynamic stochastic multi sectoral model for the world's land resources over the next century. This model brings together recent strands of agronomic, economic, and biophysical literature into a single, intertemporally consistent, analytical framework, at global scale. The model solves for the dynamic paths of alternative land uses in light of climate and technological uncertainties, which together maximize global economic welfare.

The model we develop is a discrete dynamic, finite horizon stochastic partial equilibrium model. Population, labor, physical and human capital, and other variable inputs are assumed to be exogenous. Total factor productivity and technological progress in non-land intensive sectors is also predetermined. The model focuses on the optimal allocation of scarce land across competing uses across time.

The societal objective function being maximized places value on processed food, energy services, timber products, eco-system services, and other goods and services. As the model focuses on the representative agent's behavior, the final consumption products are expressed in per-capita terms. Figure 1 shows full model's structure. The key model equations are described below, with more complete information on equations, variables, and parameter values offered in technical appendix.

\subsection{Primary Resources}

There are three primary resources in our partial equilibrium model of global economy: land, liquid fossil fuels, and other goods and services (see bottom part of Figure 1). The supply of land is fixed and faces competing uses that are determined endogenously by the model. The flow of liquid fossil fuels evolves endogenously along their optimal extraction path, accounting for exogenous discoveries in new fossil fuel reserves. Other primary inputs comprise of variable inputs, such as labor, capital (both physical and human), and intermediate materials. The endowment of other primary inputs is exogenous and evolves along prespecified global economy growth path.

\subsubsection{Land}

The total land endowment in the model, $L$, is fixed. Each period of time $t$ there are three profiles of land in the economy. They include natural forest land - 


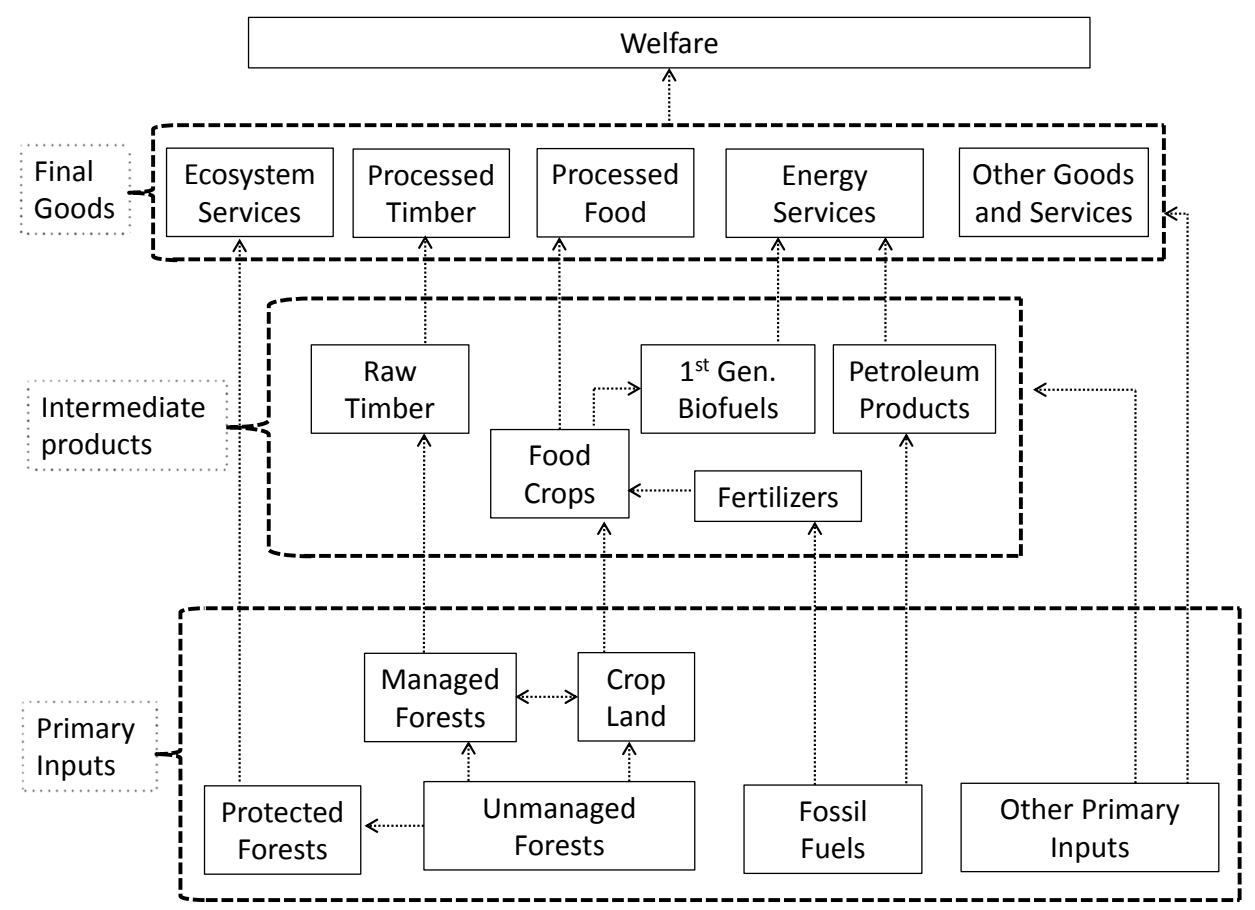

Figure 1: Structure of the Model 
which are in an undisturbed state (e.g., parts of the Amazon tropical rainforest ecosystem), agricultural cropland, $L^{A}$, and commercially managed forest land, $L^{C}$. We ignore residential, retail, and industrial uses of land in this partial equilibrium model of agriculture and forestry.

We assume that the natural forest land consists of two types. Institutionally protected land, $L^{R}$, includes natural parks, biodiversity reserves and other types of protected forests. This land is used to produce ecosystem services for society, and cannot be converted to commercial land. Unmanaged natural land, $L^{N}$, can be accessed and either converted to managed land or to protected natural land. Once the natural land is converted to managed land, its potential to yield ecosystem services is diminished and cannot be restored within the (single century) time frame of the analysis. Thus, the conversion of natural lands for commercial use is an irreversible decision. ${ }^{2}$ We denote land transition flows from unmanaged land to managed agricultural land as $\Delta^{N, A}$, and from unmanaged land to protected natural land as $\Delta^{N, R}$. The use of managed land can be shifted between forestry and agriculture. We denote land transition flows from managed forest land to agricultural land as $\Delta^{C, A}$. Note that the negative value of $\Delta^{C, A}$ implies land transition from agriculture to forestry. Equations describing allocation of land across time and different uses are as follows:

$$
\begin{gathered}
L=\sum_{i=A, C, N, R} L_{t}^{i}, \\
L_{t}^{N}=L_{t+1}^{N}-\Delta_{t}^{N, A}-\Delta_{t}^{N, R}, \\
L_{t+1}^{R}=L_{t}^{R}+\Delta_{t}^{N, R}, \\
L_{t+1}^{A}=L_{t}^{A}+\Delta_{t}^{N, A}+\Delta_{t}^{C, A},
\end{gathered}
$$

and

$$
L_{t+1}^{C}=L_{t}^{C}-\Delta_{t}^{C, A} .
$$

Equation (1) defines the composition of land in the economy. Equation (2) shows the extraction path of natural land resources and their conversion to managed or protected natural lands. Equation (3) shows the growth path of protected natural lands. Equations (4) and (5) describe the transitions between lands in agriculture and forestry.

Accessing the natural lands comes at cost, $c^{N}$, associated with building roads and other infrastructure (Golub et al., 2009). In addition, converting natural

\footnotetext{
${ }^{2}$ This point requires additional clarification. The biophysical and ecological literature suggests that restoration of forest structure and plant species takes at least 30-40 years and usually many more decades (Chazdon, 2008), costs several to ten thousands dollars per hectare (Nesshöver et al., 2009), and is only partially successful in achieving reference conditions (Benayas et al., 2009). Modeling restoration of biodiversity under these assumptions introduces greater computational complexity without making significant changes relative to findings presented in this study.
} 
land to reserved land entails additional costs, $c^{R}$, associated with passing legislation to create new natural parks. We assume that these costs are continuous, monotonically increasing, and strictly convex functions of the share of natural land previously accessed. There are no additional costs of natural land conversion to commercial land, as these costs are offset by the revenues from deforestation.

Managed Forests Managed forests are characterized by $v_{\max }$ vintages of tree species with vintage ages $v=1, \ldots, v_{\max }$. At the end of period $t$ each hectare of managed forest land, $L_{v, t}^{C}$, has an average density of tree vintage age $v$, with the initial allocation given and denoted by $L_{v, 0}^{C}$. Each period of time the managed forest land can be either planted, harvested or simply left to mature. The newly planted trees occupy $\Delta^{C, C}$ hectares of land, and reach the average age of the first tree vintage next period. The harvested area of tree vintage age $v$ occupies $\Delta_{v}^{C, H}$ hectares of forest land.

The following equations describe land use of managed forests:

$$
\begin{gathered}
L_{t}^{C}=\sum_{v=1}^{v_{\max }} L_{v, t}^{C}, \\
L_{v+1, t+1}^{C}=L_{v, t}^{C}-\Delta_{v, t}^{C, H}, \quad v<v_{\max }-1 \\
L_{v_{\max }, t+1}^{C}=L_{v_{\max }, t}^{C}-\Delta_{v_{\max }, t}^{C, H}+L_{v_{\max }-1, t}^{C}-\Delta_{v_{\max }-1, t}^{C, H} \\
L_{1, t+1}^{C}=\Delta_{t}^{C, C} .
\end{gathered}
$$

Equation (6) describes the composition of managed forest area across vintages. Equation (7) illustrates the harvesting dynamics of forest areas with the ages $v_{\max }-1$ and $v_{\max }$. Equation (9) shows the transition from planted area to new forest vintage area.

The average planting costs per hectare of newly forest planted, $c^{p}$, are invariant to scale and are the same across all vintages. Harvesting managed forests and conversion of harvested forest land to agricultural land is subject to additional near term adjustment costs, $c^{H}$.

\subsubsection{Fossil Fuels}

The initial stock of liquid fossil fuels, $X^{F}$, is exogenous, and each period of time $t$ adds a new amount of fossil fuels, $\Delta^{F, D}$, which reflects exogenous technological progress in fossil fuel exploration. ${ }^{3}$ The economy extracts fossil fuels, which have two competing uses in our partial equilibrium model of land-use. A part of extracted fossil fuels, $\Delta_{t}^{F, n}$, is converted to fertilizers that are further used in the agricultural sector. The remaining amount of fossil fuels, $\Delta_{t}^{F, E}$, is combusted to

\footnotetext{
${ }^{3}$ This technological progress comprises of both discoveries on new exploitable oil and gas fields, as well as development of new technologies for extraction of non-conventional fossil fuels.
} 
satisfy the demand for energy services. The following equation describes supply of fossil fuels:

$$
X_{t+1}^{F}=X_{t}^{F}-\Delta_{t}^{F, E}-\Delta_{t}^{F, n}+\Delta_{t}^{F, D} .
$$

The cost of fossil fuels, $c^{F}$, reflects the expenditures on fossil fuels' extraction, refining, transportation and distribution, as well the costs associated with emissions control (e.g., Pigovian taxes) in the non-land-based economy.

\subsubsection{Other Primary Resources}

The initial endowment of all other primary resources in the non-land-based economy, such as labor, physical and human capital, and materials inputs, $X^{O}$, in this model is exogenous, and grows at rate $\kappa^{o, X}$, which reflects demographic, macroeconomic, and technology developments. The following equation describes supply of other primary inputs:

$$
X_{t+1}^{O}=\kappa^{o, X} X_{t}^{O} .
$$

Other primary inputs can be used for production of land based goods and services or converted to final goods and services in the non-land economy.

\section{$2.2 \quad$ Intermediate Inputs}

We analyze five intermediate inputs used in the production land based goods and services: petroleum products, fertilizers, crops, biofuels, and raw timber (see middle part of Figure 1). Fossil fuels are refined and converted to either petroleum products that are further combusted, or to fertilizers that are used to boost yields in the agricultural sector. Cropland and fertilizers are combined to grow crops that can be further converted in food or biofuels. The biofuels substitute imperfectly for liquid fossil fuels in final energy demand. Harvesting managed forests yields raw timber that is further used in timber processing. The production function for intermediate inputs can be illustrated by the following equation

$$
x_{t}^{i}=g_{1}\left(\Delta_{t}^{F, E}, \Delta_{t}^{F, n}, L_{t}^{A}, \Delta_{v, t}^{C, H}, g_{2}\left(x_{t}^{j}\right)\right), i, j=p, n, c, b, w .
$$

Equation 12 implies that production of intermediate inputs involves the combination of primary inputs and other intermediate inputs, where $g_{1}(\cdot)$ and $g_{2}(\cdot)$ denote production functions for intermediate inputs. To preserve space we show the specific functional forms of $g_{1}(\cdot)$ and $g_{2}(\cdot)$ in technical appendix.

The production of intermediate inputs $i$ incurs non land costs, $c^{o, i}$, expressed as a fraction of other primary resources. We assume these costs are constant and scale-invariant.

\subsection{Final Goods and Services}

We consider four land based services that are consumed in the final demand: services from processed food and timber, energy services, and ecosystem services 
(see upper part of Figure 1). The processed food and timber are respectively products of crops' and raw timber industrial processing. The production of energy services combines liquid fossil fuels with the biofuels, and the resulting mix is further combusted. The ecosystem services are the public good to society, which captures recreation, biodiversity, and other environmental goods and services. We also consider other goods and services, which comprise of consumption of other primary inputs not spent on production of land based goods and services.

\subsubsection{Processed Food}

Services from processed food, $Y^{f}$, capture the efficiency gains from technology improvements in food production, which result in lower requirements for agricultural inputs in final demand. ${ }^{4}$ The conversion process is represented by the linear production function:

$$
Y_{t}^{f}=\theta_{t}^{f}\left(x^{c}-x^{c, b}\right)
$$

where $\theta_{t}^{f}$ is the productivity of the food processing sector, which captures the technological progress in both direct transformation of crops into edible food, and the storage, transportation, and distribution of processed food, and $x^{c}-x^{c, b}$ is the amount of crops that is not converted into biofuels, and processed for consumption in final demand. We assume that food processing costs, $c^{o, f}$, are exogenous and scale-invariant.

\subsubsection{Energy Services}

Biofuels, $x^{b}$, blend with petroleum products, $x^{p}$ in different proportions ${ }^{5}$, and the resulting mix further combusted to satisfy the demand for energy services. We assume that biofuels and liquid fossil fuels are imperfect substitutes. The production of energy services, $Y_{t}^{e}$, is given by CES function:

$$
Y_{t}^{e}=\theta_{t}^{e}\left(\alpha^{e}\left(x_{t}^{b}\right)^{\rho_{e}}+\left(1-\alpha^{e}\right)\left(x_{t}^{p}\right)^{\rho_{e}}\right)^{\frac{1}{\rho_{e}}}
$$

where the parameter $\theta^{e}$ describes the efficiency of energy production, (i.e., the amount of energy services provided by one unit of the energy fuel, Sorrell and Dimitropoulos 2008, p. 639), $\alpha^{e}$ is the value share of biofuels in energy production at the benchmark time 0 , and $\rho_{e}=\left(\sigma_{e}-1\right) / \sigma_{e}$ is a CES function

\footnotetext{
${ }^{4}$ For example, technological innovation in food conservation results in fewer losses from spoilage, and, correspondingly, lower amounts of processed food needed to satisfy the commercial demand for food. Correspondingly, input requirements for agricultural product also decrease.

${ }^{5}$ Blends of E10 or less are used in more than twenty countries around the world, led by the United States, where ethanol represented $10 \%$ percent of the U.S. gasoline fuel supply in 2011. Blends from E20 to E25 have been used in Brazil since the late 1970s. E85 is commonly used in the U.S. and Europe for flexible-fuel vehicles. Hydrous ethanol or E100 is used in Brazilian neat ethanol vehicles and flex-fuel light vehicles and in hydrous E15 called hE15 for modern petrol cars in Netherlands.
} 
parameter proportional to the elasticity of substitution of petroleum products for biofuels, $\sigma_{e}$.

\subsubsection{Processed Timber}

Harvested forest product, $x^{w}$ is processed for consumption in final demand. Similar to processed food, services from processed timber, $Y^{w}$, capture the efficiency gains from technology improvements in timber production, which result in lower requirements for raw timber in final demand. ${ }^{6}$ The conversion process is represented by a linear production function:

$$
Y_{t}^{w}=\theta_{t}^{s} x_{t}^{w},
$$

where $\theta^{s}$ is the productivity of timber processing sector, which captures the technological progress in both direct transformation of forest product into processed timber, and the quality improvements and durability of timber products. We assume that timber processing costs, $c^{o, s}$, are exogenous and scale-invariant.

\subsubsection{Ecosystem Services}

It is well known in both economic and ecological literatures that ecosystem services are difficult to define, and it is even more difficult to characterize their production process (National Research Council, 2005). This stems in part from the fact that there is a significant heterogeneity in ecosystem services (Costanza et al., 1997; Daily, 1997), which include physical products (e.g., subsistence food and lumber) environmental services (e.g., pollination and nutrition cycling), and non-use goods which are valued purely for their continued existence (e.g., some unobserved biodiversity). In many cases the lack of markets and market prices impedes the translation from quantities of ecosystem goods and services to their production values, and requires the application of non-market and experimental valuation techniques (Bateman et al., 2011). And there are significant differences in definitions and modeling approaches in the economic and ecological literatures, which the National Research Council 2005, p.3 refers to "the greatest challenge for successful valuation of ecosystem services". While addressing these limitations is beyond the scope of this study, given their important role in the evolution of the long run demand for land, we incorporate ecosystem services, albeit in a stylized fashion, into the global land use model determining the optimal dynamic path of land-use in the coming century.

We assume that all types of land do contribute to terrestrial ecosystem services. The output for ecosystem services, $Y^{r}$, is given by the following CES function of different land inputs:

$$
Y_{t}^{r}=\theta^{r}\left[\alpha^{A, r}\left(L_{t}^{A}\right)^{\rho_{r}}+\alpha^{C, r}\left(L_{t}^{C}\right)^{\rho_{r}}+\left(1-\alpha^{A, r}-\alpha^{C, r}\right)\left(L_{t}^{N}+\theta^{R} L_{t}^{R}\right)^{\rho_{r}}\right]^{\frac{1}{\rho_{r}}},
$$

\footnotetext{
${ }^{6}$ For example, technological innovation in durability of timber products results in their less frequent replacement. Therefore lower amounts of forest product are needed to satisfy the commercial demand for timber products.
} 
where the parameter $\theta^{r}$ describes the production "technology" of ecosystem services $^{7}$. The parameters $\alpha^{A, r}, \alpha^{C, r}$, and $1-\alpha^{A, r}-\alpha^{C, r}$ are the value shares of agricultural, managed, and natural forest lands in production of ecosystem services. The parameter $\rho_{r}=\left(\sigma_{r}-1\right) / \sigma_{r}$ is a CES function parameter proportional to the elasticity of substitution of different types of land in production of ecosystem services, $\sigma_{r}$. By characterizing the production process of ecosystem services using equation (16) we assume that agricultural, managed forest, and natural lands substitute imperfectly in production of ecosystem services. Unmanaged and protected natural land produce the same ecosystem services (Costanza et al., 1997). However, protected forest lands are more efficient in delivering many ecosystem services, as they have e.g., better management for reducing degradation of biodiversity, and better infrastructure for providing eco-tourism and recreation services (Hocking et al., 2000).

We assume that non-land cost of producing ecosystem services is zero for agricultural and managed forest land, as production of ecosystem services is not their primary function. This cost is also zero for unmanaged natural lands. As regards protected natural lands, we assume that average non-land cost of producing ecosystem services (e.g., maintenance and infrastructure expenditures) per hectare of reserved natural land, $c^{o, r}$, is exogenous and scale-invariant.

\subsubsection{Other Final Goods and Services}

The amount of other primary resources that is not spent on production of land based goods and services is converted into other goods and services. These other goods and services are consumed in final demand. As the the focus of this model is on utilization of land based resources we introduce the other goods and services in a very simplified manner. Specifically we assume that production of other goods and services is a linear function of other primary inputs net of land based expenditures:

$$
Y_{t}^{o}=\theta_{t}^{o}\left[\begin{array}{c}
X_{t}^{O}-c^{o, c} \frac{x_{t}^{c}}{\theta_{t}^{c}}-c^{o, f} \frac{Y_{t}^{f}}{\theta_{t}^{f}}-c^{o, p} x_{t}^{p}-c^{o, n} x_{t}^{n}-c^{o, b} x_{t}^{b}-c_{t}^{o, w} \Delta_{t}^{C, H} \\
-c^{o, s} x_{t}^{w}-c^{o, r} L_{t}^{R}-c^{p} \Delta_{t}^{C, C}-c_{t}^{N}-c_{t}^{R}-c_{t}^{F}-c_{t}^{H}
\end{array}\right],
$$

where the parameter $\theta_{t}^{o}$ is the economy's total factor productivity. We introduce no additional cost of producing other goods and services, assuming that it is reflected in the size of endowment of other primary inputs.

\subsection{Preferences}

The economy's total utility of the population, $U$, is derived from the per capita consumption of processed food and timber, energy and ecosystem services, and

\footnotetext{
${ }^{7}$ We put the term "technology" in quotation terms because, as discussed above, characterizing "true" production process of ecosystem services is beyond the scope of the paper. Here we use the term "technology" as a scalar that maps ecological assets to ecosystem services in reference period 0 .
} 
other goods and services. Following the macro economic literature, we assume constant relative risk aversion utility,

$$
U\left(\overrightarrow{y_{t}}\right)=\frac{\left(u\left(\overrightarrow{y_{t}}\right)\right)^{1-\gamma}}{1-\gamma} \Pi_{t},
$$

where $\overrightarrow{y_{t}}=\left(y_{t}^{f}, y_{t}^{e}, y_{t}^{w}, y_{t}^{r}, y_{t}^{o}\right)=\left(Y_{t}^{f}, Y_{t}^{e}, Y_{t}^{w}, Y_{t}^{r}, Y_{t}^{o}\right) / \Pi_{t}$ is the per capita consumption bundle, $\Pi_{t}$ is the economy's population, and $\gamma$ is the coefficient of relative risk aversion, which captures the economy's attitude to uncertain events.

The specific functional form for the utility function, $u\left(\overrightarrow{y_{t}}\right)$, is based on implicitly directive additive preferences, AIDADS (Rimmer and Powell, 1996). Our choice of the utility function is motivated by its several important advantages of AIDADS preferences over other functional forms underpinning standard models of consumer demand. First, similar to the well-known AIDS demand system (Deaton and Muellbauer, 1980) the AIDADS model is flexible in its treatment of Engel effects, as the model "allows the MBS' (Marginal Budget Shares) to vary as a function of total real expenditures" Rimmer and Powell (1996, p. 1614). Second, the AIDADS has global regularity properties, in contrast to the local properties of $\operatorname{AIDS}^{8}$. This is essential for solution of the model over a wide range of quantities. A number of studies (Cranfield et al., 2003; Yu et al., 2004) demonstrated that AIDADS outperforms other popular models of consumer demand in projecting global food demand, which makes it especially well-suited for the economic modeling of land-use.

The utility function for the AIDADS system is the implicitly directly additive function (Hanoch, 1975; Rimmer and Powell, 1996):

$$
u\left(\overrightarrow{y_{t}}\right)=\exp \left[\sum_{q=f, e, w, r, o}\left(\frac{\alpha_{q}+\beta_{q} \exp \left(u\left(\overrightarrow{y_{t}}\right)\right)}{1+\exp \left(u\left(\overrightarrow{y_{t}}\right)\right)}\right) \log \left(y_{t}^{q}-\underline{y}^{q}\right)\right],
$$

where $u$ is the utility level obtained from the consumption of goods or services $q$, and the parameters $\alpha_{q}$ and $\beta_{q}$ define the varying marginal budget shares of goods and services in the consumers' total real expenditures. The parameter $\underline{y}^{q}$ defines the subsistence level of consumption of goods and services $\vec{y}$. Equation 19 implies that the consumption of goods and services $\vec{y}$ is always greater than their subsistence levels. The AIDADS system imposes standard non-negativity and adding-up restrictions based on the economic theory. These restrictions ensure that the consumers' marginal budget shares and minimal consumption level of goods and services $\underline{y}^{q}$ are greater or equal to zero, and the sum of marginal budget shares in total real expenditures does not exceed one.

\footnotetext{
${ }^{8}$ One of well-known limitations of the AIDS system is that its budget shares fall outside $[0,1]$ interval. This frequently occurs when AIDS is applied to model the demand for staple food when income growth is large (Yu et al., 2004, p. 102).
} 


\section{Modeling Uncertainty}

This section characterizes dynamic uncertainty in agricultural yields over the coming century and embeds this uncertainty into the model's optimization stage. Crop yields are subject to two types of uncertainties: those related to the development and dissemination of new technologies, and those related to changes in the climatic conditions under which the crops are grown. These two sources of uncertainty are treated separately, although they are both characterized through the use of combined climate and crop simulation models run over a global grid. In addition, this section discusses the method for solving this dynamic-stochastic model of global land use.

\subsection{Functional Representation of Uncertainty}

We characterize future uncertainty in yields via a crop productivity index, $\theta_{t}^{c}$. The first stylized fact about staple grains yields in the agronomic literature is that they tend to grow linearly, adding constant amount of gain (e.g., ton/ha) each year. This suggests that the proportional growth rate should fall gradually over time. However, crop physiology dictates certain biophysical limits to the rate at which sunlight and soil nutrients can be converted to grain. And there is some recent agronomic evidence (Cassman et al., 2010; Grassini et al., 2013) showing that yields appear to be reaching a plateau in some of the world's most important cereal-producing countries. Cassman (1999) suggest that average national yields can be expected to plateau when they reach $70-80 \%$ of the genetic yield potential ceiling. Based on these observations from agronomic literature we specify the following logistic function determining the evolution of the crop productivity index over time:

$$
\theta_{t}^{c}=\frac{\theta_{T}^{c} \theta_{0}^{c} e^{\kappa_{c} t}}{\theta_{T}^{c}+\theta_{0}^{c}\left(e^{\kappa_{c} t}-1\right)},
$$

where $\theta_{0}^{c}$ is the value of the crop productivity index in period $0, \theta_{T}^{c}$ is the crop yield potential in the end of the current century, i.e., "the yield an adapted crop cultivar can achieve when crop management alleviates all abiotic and biotic stresses through optimal crop and soil management" (Evans and Fischer, 1999), and $\kappa_{c}$ is the logistic convergence rate to achieving potential crop yields.

Though the initial value of the crop productivity index is known with certainty, potential crop yields are highly uncertain. We assume that potential crop yields are subject to technological and climate shocks $\epsilon_{i, t}$, which are uncorrelated and independently and identically distributed across time with probability $p_{s}:=\mathbb{P}\left(\epsilon_{t}=\epsilon^{s}\right)$, where state $s \in\{1, \ldots, S\}$. Specifically, we assume that potential crop yields can take two states for realization of each shock - the optimistic (high yield) state, indexed by $h$, and pessimistic (low yield) state, indexed by $l$, i.e., $s \in\{h, l\}$. Under these assumptions, the probability that, after realization of a technology or climate shock, the potential crop yield takes on the pessimistic state is $p_{i}:=\mathbb{P}\left(\epsilon_{i, t}=\epsilon^{l}\right)$, where $i \in\{1,2\}$, and the probability that the potential crop yield takes on an optimistic state is $1-p_{i}$. Furthermore, we 
treat these adverse climate and technology shocks as being irreversible "tipping" events. Therefore, once the pessimistic state is realized it remains in place until the end of model solution period.

The stochastic transition path of the crop productivity index is given by

$$
\begin{aligned}
\theta_{t+1}^{c}= & \left(1-J_{1, t}\right)\left(1-J_{2, t}\right) \frac{\theta_{T}^{c, h h} \theta_{0}^{c} e^{\kappa_{c} t}}{\theta_{T}^{c, h h}+\theta_{0}^{c}\left(e^{\kappa_{c} t}-1\right)}+ \\
& J_{1, t}\left(1-J_{2, t}\right) \frac{\theta_{T}^{c, l h} \theta_{0}^{c} e^{\kappa_{c} t}}{\theta_{T}^{c, l h}+\theta_{0}^{c}\left(e^{\kappa_{c} t}-1\right)}+ \\
& \left(1-J_{1, t}\right) J_{2, t} \frac{\theta_{T}^{c, h l} \theta_{0}^{c} e^{\kappa_{c} t}}{\theta_{T}^{c, h l}+\theta_{0}^{c}\left(e^{\kappa_{c} t}-1\right)}+ \\
& J_{1, t} J_{2, t} \frac{\theta_{T}^{c, l l} \theta_{0}^{c} e^{\kappa_{c} t}}{\theta_{T}^{c, l l}+\theta_{0}^{c}\left(e^{\kappa_{c} t}-1\right)},
\end{aligned}
$$

where $J_{1, t}$ and $J_{2, t}$ are two independent discrete Markov chains, each having two possible values: $J_{i, t}=0$ indicating that shock $\epsilon_{i, t}$ did not realize the state $l$ by time $t$, and $J_{i, t}=1$ indicating that shock $\epsilon_{i, t}$ achieved the state $l$ by time $t$, for $i=1,2$, where $J_{1, t}$ represents the climate change tipping and $J_{2, t}$ represents the technological change tipping. The probability transition matrix of $J_{i, t}$ from period $t$ to period $t+1$ is

$$
\left[\begin{array}{cc}
1-p_{i, t} & p_{i, t} \\
0 & 1
\end{array}\right],
$$

where its $(i, j)$ element is the transition probability from state $h$ to $l$, and $p_{i, t}$ is the probability that the state $l$ from the shock $\epsilon_{i, t}$ happens in period $t$.

\subsection{Quantifying the Uncertainty in Crop Yields}

\subsubsection{Uncertainty in Agricultural Technology}

As noted previously, we separate technological uncertainty from climate impacts uncertainty in projecting the future state of crop productivity. Advances in crop technology are very difficult to predict due to four interconnected factors (Fischer et al., 2011). First, there is a significant uncertainty about the potential for exploiting large and economically significant yield gaps (i.e., the differences between observed and potential crop yields) in developing countries, especially in sub-Saharan Africa. A second, and closely related point is that it is unclear how fast available yield enhancing technologies can be adopted at global scale. ${ }^{9}$ Third, there is a significant variation in developing countries' institutions and policies that make markets work better and provide a conducive environment for agricultural technology adoption. ${ }^{10}$ Finally, while plant breeders continue

\footnotetext{
${ }^{9}$ These technologies include conservation farming approaches based on no-tillage, the genetic modification technology revolution, and information and communication technologies for more efficient and precise management of modern inputs.

${ }^{10}$ These best practices include adoption of better risk management, market development, rural finance, farmers' organizations and the provision of advisory services to farmers.
} 
to make steady gains in further advancing crop yields, progress depends on the level of funding provided for agricultural research. This has proven to be somewhat volatile, with per capita funding falling in the decades leading up to the recent food crisis (Alston and Pardey, 2014). The recent food price rises have stimulated new investments. However, whether this interest will be sustained remains to be seen. Overall, progress from conventional breeding is becoming more difficult. Transgenic (genetic modification) technologies have a proven record of more than a decade of safe and environmentally sound use, and thus offer huge potential to address critical biotic and abiotic stresses in the developing world. However, expected yield gains, costs of further developing these technologies, and the political acceptance of genetically modified foods are all highly uncertain.

To quantify the extent to which the advances in crop technology can further boost agricultural yields over the course of next century, we first need to assess the magnitude of existing yield gaps at global scale. In a comprehensive study Lobell et al. (2009) report a significant variation in the ratios of actual to potential yields for major food crops across the world, ranging from 0.16 for tropical lowland maize in Sub-Saharan Africa to 0.95 for wheat in Haryana, India. For the purposes of this study we employ the results of Licker et al. (2010), who conduct comprehensive yield gap analysis using global crop dataset of harvested areas and yields for 175 crops on a $0.5^{\circ}$ geographic grid of the planet for the year 2000. Using these estimates we calculate the global yield gap as the grid-level output-weighted yield gap of the four most important food crops (wheat, maize, soybeans, and rice). The resulting estimate suggests that average yields are $53 \%$ of potential yields, which is close to the median of Lobell et al. (2009) results. As a further robustness check we employ the Decision Support System for Agrotechnology Transfer (DSSAT) crop simulation model (Jones et al., 2003), run globally on a 0.5 degree grid in the parallel System for Integrating Impacts Models and Sectors (pSIMS; Elliott et al. 2014) to simulate yields of the same four major food crops under best agricultural management conditions and compare simulated yields to their observed yields. The resulting yield gap estimates were not substantially different.

In the optimistic state of advances in crop technology we assume that yields continue to grow linearly throughout the coming century, eliminating the yield gap by 2100. This high yield scenario rests on the assumption of continued strong growth in investment in agricultural research and development, widespread acceptance of GMOs, continuing institutional reforms in developing countries, and public and private investments in dissemination of new technologies. The erosion of any one of these component assumptions will likely result in a slowing of crop technology improvements. And there are some reasons for pessimism. In a comprehensive statistical analysis of historic crop production trends Grassini et al. (2013) note that

"despite the increase in investment in agricultural R\&D and education [...] the relative rate of yield gain for the major food crops has decreased over time together with evidence of upper yield plateaus 
in some of the most productive domains. For example, investment in $R \& D$ in agriculture in China has increased threefold from 1981 to 2000. However, rates of increase in crop yields in China have remained constant in wheat, decreased by $64 \%$ in maize as a relative rate and are negligible in rice. Likewise, despite a $58 \%$ increase in investment in agricultural R\&D in the United States from 1981 to 2000 (sum of public and private sectors), the rate of maize yield gain has remained strongly linear."

To capture the possibility of much slower technological improvement in the coming century, we specify a pessimistic scenario in which, rather than closing the yield gap by 2100 , average yields in 2100 are just three-quarters of potential at that point in time. As previously noted, we then specify a given probability with which the crop technology index will irreversibly deteriorate from the optimistic to the pessimistic path.

\subsubsection{Uncertainty in Climate Change Impacts}

In addition to crop technology uncertainty, there is great uncertainty about the physical environment in which this technology will be deployed. In particular, long run changes in both temperature and precipitation are likely to have an important impact on the productivity of land in agriculture (IPCC, 2014), and therefore the global pattern of land use. Quantification of the impact of climate change on agricultural yields requires coming to grips with three interconnected factors (Alexandratos, 2011). First, there is a significant uncertainty in future GHG concentrations along the long run growth path of the global economy. Second, the General Circulation Models (GCMs) developed by climate scientists to translate these uncertain GHG concentrations into climate outcomes disagree about the spatially disaggregated deviations of temperature and precipitation from baseline levels. Finally, there is a significant uncertainty in the biophysical models used to determine how changes in temperature and precipitation will affect plant growth and the productivity of agriculture in different agro-ecological conditions. The impact of climate change on food crop yields depends critically on their phenological development, which, in turn, depends on the accumulation of heat units, typically measured as growing degree days (GDDs). More rapid accumulation of GDDs as a result of the climate change speeds up phenological development, thereby shortening key growth stages, such as the grain filling stage, hence reducing potential yields (Long, 1991). However, raising concentrations of $\mathrm{CO}_{2}$ in the atmosphere results in an increase in potential yields due to the " $\mathrm{CO}_{2}$ fertilization effect" (Long et al., 2006). Sorting out the relative importance of these effects and achieving more robustness in evaluating climate impacts on agricultural yields remains an important research question in agronomic and biophysical literatures (Cassman et al., 2010; Rosenzweig et al., 2014).

To quantify the uncertainty in climate impacts on agricultural yields we follow the approach of Rosenzweig et al. (2014), who have recently conducted a 
Table 1: Changes in Potential Crop Yields by 2100 (t / Ha)

\begin{tabular}{lcccc}
\hline Model / Scenario & RCP 2.6F & RCP2.6NF & RCP 8.5F & RCP 8.5NF \\
\hline GFDL-ESM2M & 0,17 & $-0,16$ & 0,46 & $-0,72$ \\
HadGEM2-ES & 0,16 & $-0,18$ & $-0,27$ & $-1,30$ \\
IPSL-CM5A-LR & 0,04 & $-0,29$ & $-0,27$ & $-1,30$ \\
MIROC-ESM-CHEM & $-0,03$ & $-0,34$ & $-0,34$ & $-1,32$ \\
NorESM1-M & 0,20 & $-0,12$ & 0,16 & $-0,92$ \\
\hline
\end{tabular}

Notes. F: Fertilization Effect; NF: No Fertilization Effect.

The results are normalized relative to $\theta_{T}^{c}=8.8$.

globally consistent, protocol-based, multimodel climate change assessment for major crops with explicit characterization of uncertainty. To quantify the range of uncertainty of climate change impact on potential crop yields we obtained results from the DSSAT crop simulation model, run globally on a $0.5^{\circ}$ grid and weighted by agricultural output of four major food crops (maize, soybeans, wheat and rice) under most optimistic (RCP2.6) and pessimistic (RCP8.5) Representative Concentration Pathways GHG forcing scenarios (Moss et al., 2008) and alternate assumptions on $\mathrm{CO}_{2}$ fertilization effects over the period between 1971 and 2099. To quantify uncertainty in temperature increases due to climate change we employ outputs for five global climate models (GCM): GFDLESM2M (Dunne et al., 2013), HadGEM2-ES (Collins et al., 2008), IPSL-CM5ALR (Dufresne et al., 2012), MIROC-ESM-CHEM (Watanabe et al., 2011), and NorESM1-M (Bentsen et al., 2012). For each of the simulations we fit a linear trend in order to parsimoniously characterize the evolution of crop yields in the face of climate change over the coming century.

Table 1 summarizes simulation results for four climate scenarios (RCP 2.6 and 8.5 with and without fertilization effects) in 2100 , normalized relative to an assumed yield potential of $8.8 \mathrm{t} / \mathrm{Ha}$. There is a significant heterogeneity in terms of both direction and magnitude of climate impacts on agricultural yields across global climate models when the $\mathrm{CO}_{2}$ fertilization effect is considered. For the most optimistic scenario, RCP2.6 with fertilization effects (RCP2.6F), four out of five GCMs predict an increase in potential yields, whereas one model (MIROC-ESM-CHEM), predicts a very small decline in potential yield. In a scenario of rapid increases in global temperature with $\mathrm{CO}_{2}$ fertilization effects (RCP8.5F) three out of five GCMs predict a decline in potential yields of comparable magnitude (between 0.27 and $0.34 \mathrm{t} / \mathrm{Ha}$ ). Another GCM (NorESM1-M) predicts an increase in potential yields, but to a lesser extent as compared to scenario RCP2.6F. Only one climate model (GFDL-ESM2M) predicts an increase in potential yields, which is greater than in scenario $\mathrm{RCP} 2.6 \mathrm{~F}$. These results are consistent with recent findings of Rosenzweig et al. (2014), who show the potential for negative climate impacts on major crops at higher levels of warming.

The predictions of global climate models become qualitatively more similar 
when $\mathrm{CO} 2$ fertilization effects are removed. For a scenario of moderate temperature increases without fertilization effects (RCP2.6NF), all GCMs predict a moderate decline in potential yields (between 0.12 and $0.34 \mathrm{t} / \mathrm{Ha}$ ). Three out of five GCMs predict a decline in potential yields of a comparable magnitude to scenario RCP8.5F. Finally, for a scenario of rapid temperature increases without fertilization effects (RCP8.5NF), all GCMs predict a larger decline in potential yields (between 0.72 and $1.32 \mathrm{t} / \mathrm{Ha}$ ). These results are consistent with recent statistical evidence showing that " 10 years of climate trend is equivalent to a setback of roughly 1 year of technology gains" (Lobell et al., 2011, p. 619).

Based on these results we construct 2 states for potential crop yields under climate scenarios. Under the optimistic state of the world, we observe moderate temperature increases with significant $\mathrm{CO}_{2}$ fertilization effects (RCP $2.6 \mathrm{~F}$ climate scenario), resulting in small increases in crop yields, relative to baseline. This is the path on which we begin the simulation in 2004. In each period, there is a distinct probability of irreversibly deteriorating to the pessimistic state in which more rapid temperature increases and ineffective $\mathrm{CO}_{2}$ fertilization (RCP8.5NF climate scenario) result in a significant decline in crop yields by 2100 .

\subsubsection{Constructing Stochastic Crop Productivity Index}

Having characterized the realizations of crop productivity under alternative states of the agricultural technology and the climate change, we still need to assign transition probabilities for tipping from the baseline to possible low yields states to construct the stochastic crop productivity index. As the long term evolution of both the advances in crop productivity and climate change impacts are nearly impossible to forecast, we set the one-period probabilities of falling to pessimistic state $p_{1, t}=p_{2, t}=0.34 \%$ for all $t$, so that the accumulated probability of each state $\{h h, l h, h l, l l\}$ is equal by the end of the model solution period.

Figure 2 shows the expected path of the stochastic crop productivity index, and the range of all sample paths of this index over the course of next century. The accumulated probability of both pessimistic states happening is about $25 \%$ by 2200 ( $8.5 \%$ by 2100), and the accumulated probability of at least one of the pessimistic states happening is about $75 \%$ by 2200 (29\% by 2100). We view this as a relatively conservative specification of tipping points.

\subsection{Welfare}

The objective of the planner is to maximize the total expected welfare, which is the cumulative expected utility of the population's consumption of final goods and services, $\vec{y}$, discounted at the constant rate $\delta>0$, and the expected bequest value of unmanaged natural forests and managed forests. ${ }^{11}$ The planner

\footnotetext{
${ }^{11}$ We do not consider the bequest value of protected forests, as they cannot be "scrapped" in our model.
} 


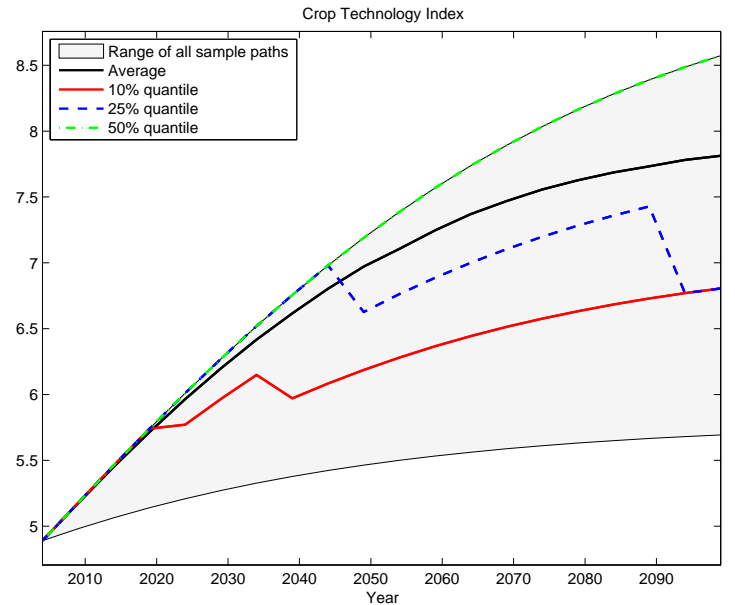

Figure 2: Stochastic Crop Productivity Index

allocates managed agricultural and forest lands for crop and timber production, the scarce fossil fuels and protected natural forests to solve the following problem:

$$
\max _{\Delta, \vec{y}} \sum_{t=0}^{T-1} \delta^{t} \mathbb{E}\left\{U\left(\overrightarrow{y_{t}}\right)\right\}+\delta^{T} \mathbb{E}\left\{\Gamma\left(L_{T}^{U}, L_{T}^{C}\right)\right\}
$$

subject to constraints (1)-(19), where $\Gamma$ is the scrap value function and $\Delta$ represents the change of land and fossile fuel, i.e., $\Delta^{N, A}, \Delta^{N, R}, \Delta^{C, A}, \Delta^{C, H}, \Delta^{C, C}, \Delta^{F, E}, \Delta^{F, n}$.

\subsection{Method of Solution}

The dynamic programming formulation of the model is the following Bellman equation Bellman (1957):

$$
\begin{gathered}
V_{t}\left(L_{t}^{N}, L_{t}^{A}, L_{t}^{R}, L_{t}^{C}, X_{t}^{F}, \theta_{t}^{c}\right)= \\
\max _{\Delta_{t}, \overrightarrow{y_{t}}} U\left(\overrightarrow{y_{t}}\right)+\delta \mathbb{E}\left\{V_{t+1}\left(L_{t+1}^{N}, L_{t+1}^{A}, L_{t+1}^{R}, L_{t+1}^{C}, X_{t+1}^{F}, \theta_{t+1}^{c}\right)\right\},
\end{gathered}
$$

subject to constraints (1)-(19), for $t<T$. The terminal value function $V_{T}=\Gamma$ is given by computing the discounted summation of payoffs with fixed control policies over the period $[T+1, T+200]$, for each possible terminal state vector $\left(L_{T}^{N}, L_{T}^{A}, L_{T}^{R}, L_{T}^{C}, X_{T}^{F}, \theta_{T}^{c}\right)$. Here $L^{C}$ represents the $v_{\max }$ dimensioanl vector of the managed forest land of all vintage ages.

We solve the stochastic problem by numerical dynamic programming algorithms with value function iteration (Cai and Judd (2010)). Since this is a 
high-dimensional problem containing one discrete state $\theta^{c}$ and $\left(v_{\max }+4\right)$ continuous state vector, $\left(L^{N}, L^{A}, L^{R}, L^{C}, X^{F}\right)$, we apply the parallel value function iteration method (Cai et al. (2013)) in a supercomputer for solving it. More discussion of numerical dynamic programming is given in the technical appendix.

\section{Model Results}

This section describes the results of the impact of crop yield uncertainty on the optimal path of global land use based on dynamic stochastic model simulations. We solve the model over the period $2005-2204$, and present the results for the first 100 years to minimize the effect of terminal period conditions on our analysis. We first present the results of the perfect foresight model, where the optimal land allocation decisions are made based on the values of crop productivity index in the absence of climate and technology shocks. This deterministic analysis is a useful reference point for further discussion when the uncertainty in food crop yields is introduced. We then present the results of the dynamic stochastic model, where the impact of the intrinsic climate and technology uncertainty is brought into the model optimization stage. Specifically, we use equation 23 to generate 1000 sample paths of optimal global land use under different realizations of the stochastic crop productivity index. The results are presented as the difference between the stochastic path and deterministic reference solution.

\subsection{Optimal Path of Global Land Use under Climate and Technology Uncertainty}

Figure 3 depicts the optimal allocation of global land-use, over the course of next century. The left-hand side of figure 3 shows the model baseline path of different types of land considered in this study when the food crop yields are are perfectly anticipated (no uncertainty). The right-hand side of figure 3 shows the difference range between the model deterministic baseline path and alternative paths corresponding to different realizations of the stochastic crop productivity index.

Beginning with the upper panel of Figure 3, we see that, in the near term decades, area dedicated to food crops increases by 200 million hectares or 13 percent compared to 2004, reaching its maximum of 1.73 billion hectares around 2040. Continuing population growth and increasing demand for food stemming from economic growth are the key drivers for this cropland expansion. In the second half of the coming century, slower population growth, and technology improvements in crop yields and food processing result in a smaller demand for cropland. By 2100 cropland area declines to 1.59 billion hectares, which is just 4 percent larger than in 2004. Uncertainty in the crop productivity index results in additional land conversion aimed at offsetting the impact of potentially lower yields. However, the magnitude of this cropland use effect is relatively small. Along the most extreme paths of the stochastic crop productivity index, which imply rapid realizations of climate and technology shocks, the difference 
relative to the baseline land use path is about 30 million hectares, which is about 2 percent of the total crop land in 2004. The difference declines rapidly as the likelihood of climate and technology shocks diminishes.

a)
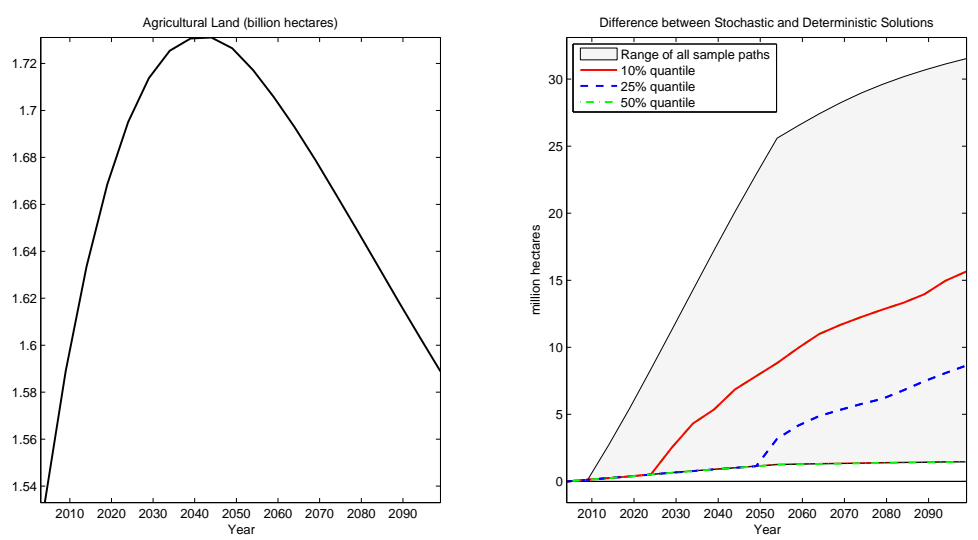

b)
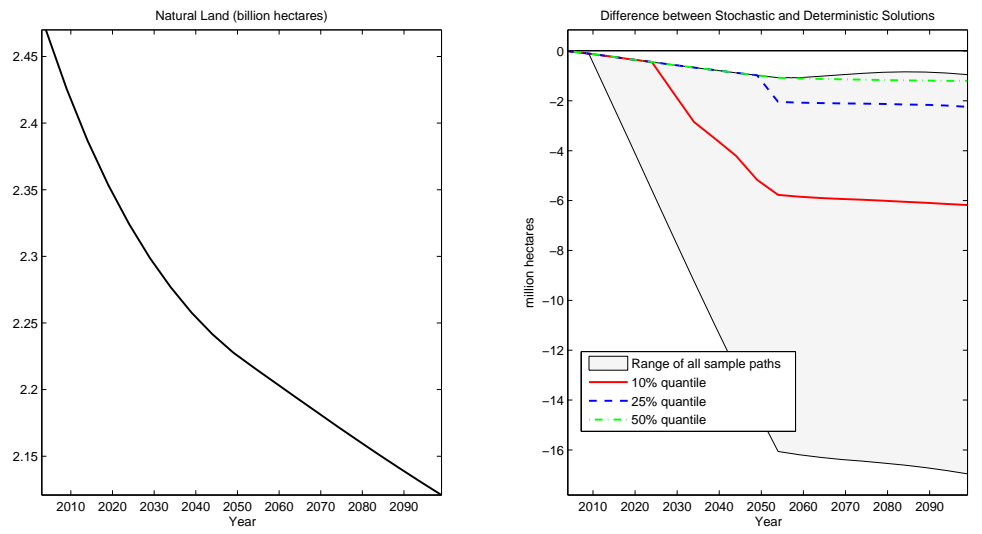
c)
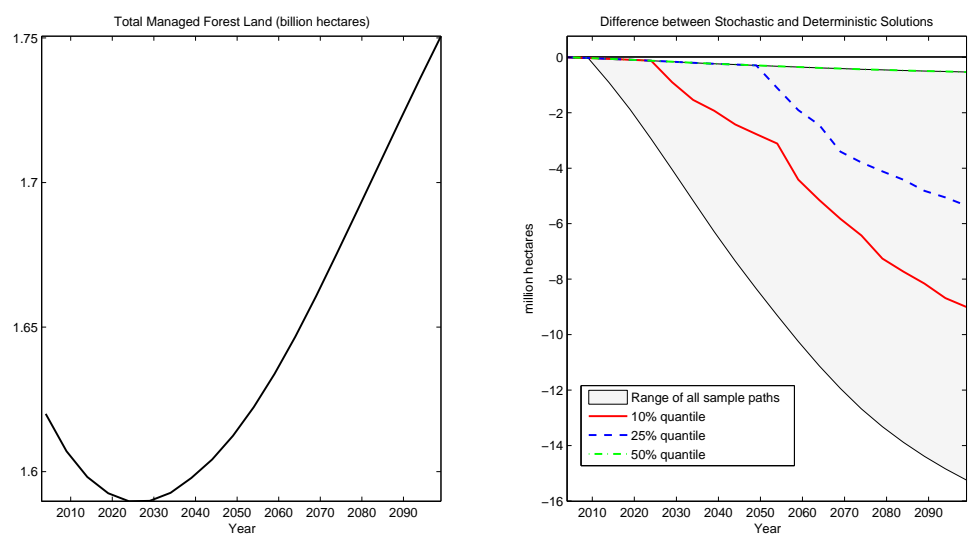

d)
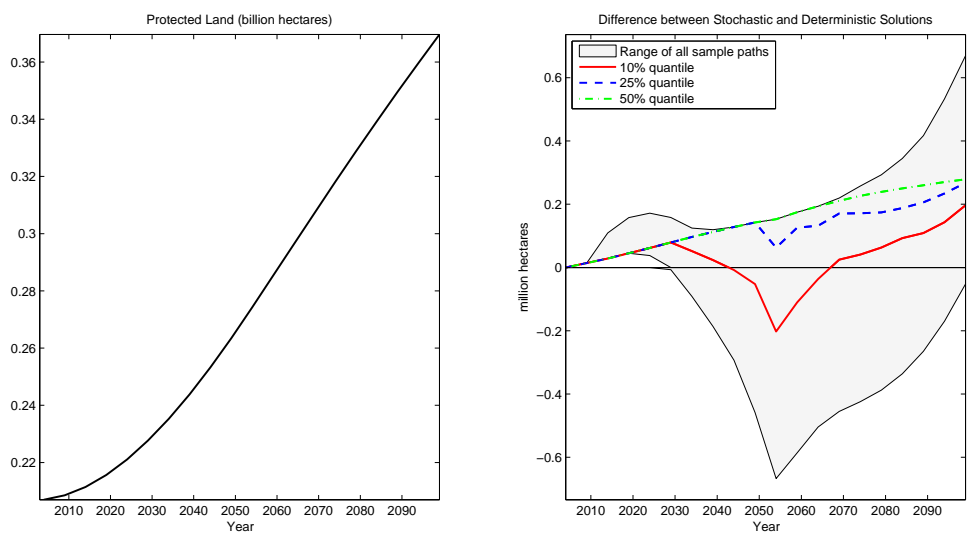

Figure 3: Optimal Global Land Use Path under Perfect Foresight of Crop Productivity

The expansion in cropland is associated with significant losses in unmanaged natural land (panel b), which declines by 220 million hectares (or by 9 percent compared to 2004) around 2040. Managed forest area declines by a small amount in near decades and then increases, returning to its 2004 levels by mid-century (panel c). In the second half of the coming century growing demand for timber products results in a stronger growth in managed forest land. Managed forest area increases to 1.75 billion hectares by the end of the century, which is 8 percent larger than in 2004. Unmanaged forest area continues to decline, although at slower pace in the second half of the century, falling to 2.11 billion hectares, which is 18 percent small than in 2004. The decline in unmanaged forest land is less environmentally damaging in the second half of the coming century, as deforestation does not occur, and most of that land is converted to managed 
or protected forest land. Uncertainty in crop productivity index is associated with near identical developments in the optimal paths of managed forest and unmanaged natural forest lands (panels b and c). Each type of land declines around the pessimistic realizations of the stochastic crop productivity index, accounting for about 50 percent in variation of the crop land use.

Protected forest area grows moderately in near decades adding 50 million hectares by mid century (panel d). In the second part of the coming century, demand for ecosystem services grows strongly, resulting in a considerable expansion of protected natural land areas. By 2100 protected natural forest area reaches 0.37 billion hectares, which is 85 percent larger than in 2004. The optimal path of protected natural land under climate and crop productivity uncertainty is little changed.

\subsection{Optimal Path of Land Based Goods and Services un- der Climate and Technology Uncertainty}

Figure 4 presents the optimal path of land based goods and services. The lefthand side of figure 4 shows the model baseline path of different types of land based goods and services when the food crop yields are perfectly anticipated. The right-hand side of figure 4 shows the difference range between the model deterministic baseline path and alternative paths corresponding to different realizations of the stochastic crop productivity index.

The upper panel of Figure 4 shows optimal path of food crops, which increases steadily in the first half of the coming century. Compared to 2004, production of food crops increases by more than 2 billion tons or 32 percent, reaching its maximum of 9 billion tons around 2045. As with cropland expansion rapid population growth and increasing demand for food at subsistence level are the key drivers for growing consumption on the demand side. On the supply side, the increase in production of food crops is further boosted by growing crop yields. In the second half of the coming century, production of food crops moderates, as consumers satiate their food requirements and the technology of food marketing and processing improves. By 2100 crop production for foodstuffs declines to 7.8 billion tons, which is just 13 percent larger than in 2004 . Uncertainty in crop productivity index has a strong effect on the optimal path of food crops. Along the most extreme paths of the stochastic crop productivity index, the production of food crops is about 2.6 billion tons less compared to the deterministic path of the stochastic crop productivity index. This is a large change indeed, and suggests higher levels of malnutrition in 2100. Almost all of the variation in the optimal path of food crops comes on the demand side. As shown above the supply response is small along the extensive margin. In the technical appendix (Figure D.1, panel a) we show that the supply response on the intensive margin is even smaller, with the ratio of fertilizers to cropland increasing by less than one percent under extreme realizations of climate and technology uncertainty. This result indicates that uncertainty in crop productivity has a profound impact on demand for food over the coming century, and potentially has strong and negative welfare implications (Hertel et al., 2010c). 
a)
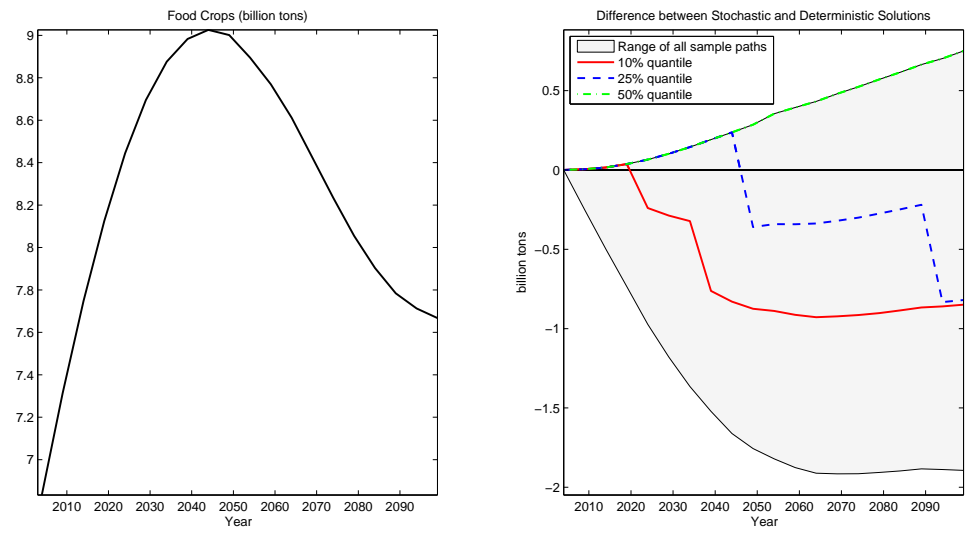

b)
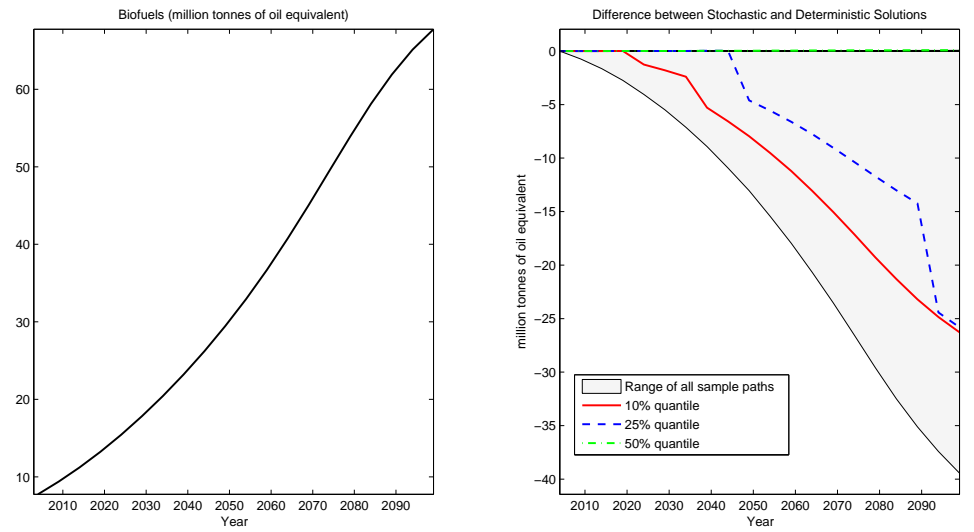
c)
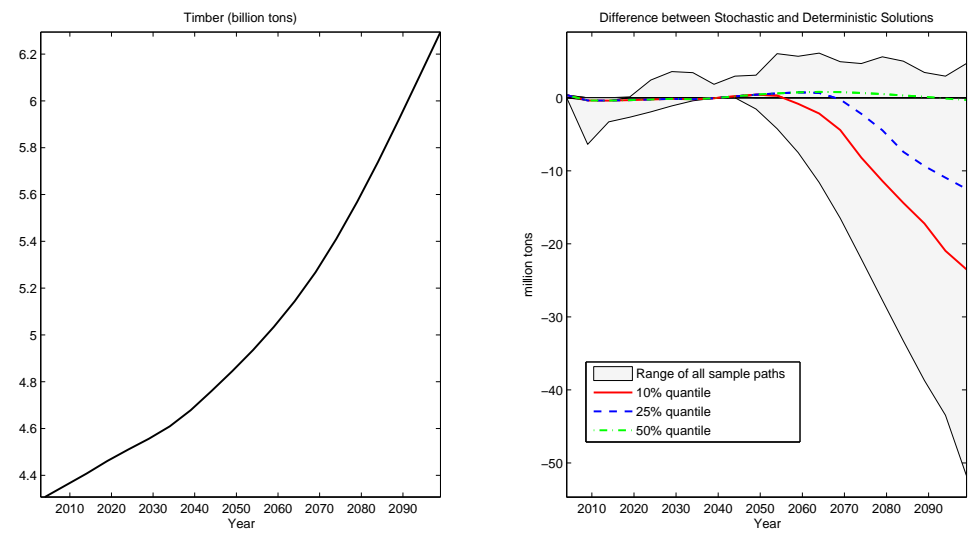

d)
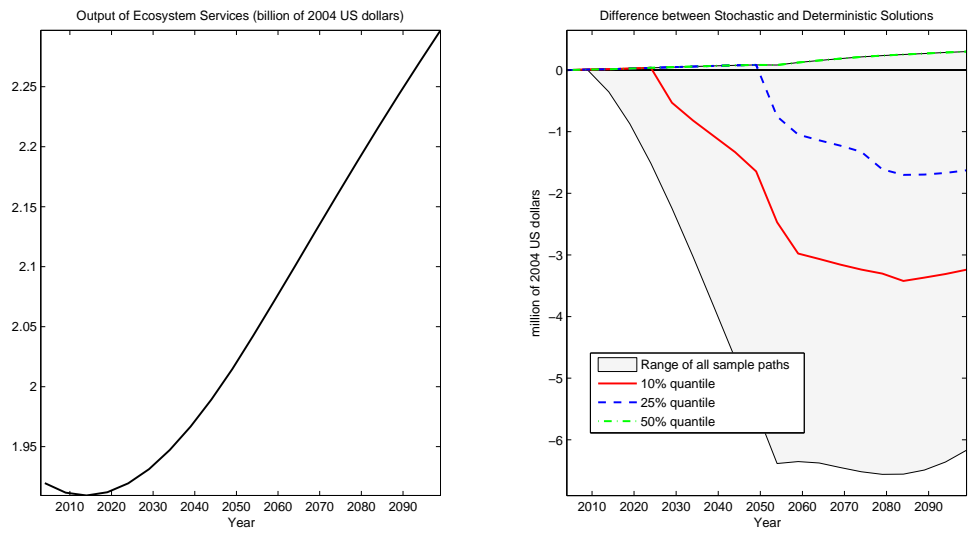

Figure 4: Optimal Path of Land-Based Goods and Services under Uncertain Crop Productivity 
The production of first generation biofuels grows as oil becomes more scarce along the baseline path and agricultural yields increase (panel b). However, along this optimal path, first generation biofuels still do not become a large source of energy consumption. In 2100 the production of first generation biofuels is 55 Mtoe, considerably higher than in 2004, but still small in relative terms (less than $1.5 \%$ of total liquid fuel consumption: see technical appendix, Figure D.1, panel b). Nonetheless, uncertainty in food crop yields has important implications for the first generation biofuels. The difference between the most optimistic and pessimistic states of the crop productivity index is about 35 million tons of oil equivalent, which is a large fraction (63 percent) of their expected consumption in 2100 .

The production of raw timber expands with growing demand for timber products and further improvements in forest yields (panel c). By 2100, production of merchantable timber crops reaches to 6.2 billion tons, which is 46 percent larger than in 2004. The consumption of ecosystem services declines in the near decades as unmanaged natural forest lands are converted to crop lands (panel d). It then increases throughout the remaining part of the coming century as the demand for ecosystem services increases and more natural forest lands become institutionally protected. By 2100 consumption of ecosystem services is 18 percent larger than in 2004. Crop productivity uncertainty has very small impact on the consumption of merchantable timber and ecosystem services (panels c and d).

\section{Conclusions}

The pattern of global land use has important implications for the world's food and timber supplies, bioenergy, biodiversity and other eco-system services. However, the productivity of this resource is critically dependent on the world's climate, as well as investments in, and dissemination of improved technology. This creates massive uncertainty about future land use requirements which compound the challenge faced by individual investors and governments seeking to make long term, sometimes irreversible investments in land conversion and land use. In this paper, we assess how the uncertainties associated with the underlying biophysical processes and technological change in agriculture affect the optimal profile of land use over the next century. To do so, we develop is a long-run dynamic stochastic partial equilibrium model, which brings together distinct strands of economic, agronomic, and biophysical literature and incorporates key drivers affecting global land-use, and solve it using recent state of art methods in parallel dynamic programming.

To quantify the uncertainty in climate impacts on agricultural yields, we use the results from the Decision Support System for Agrotechnology Transfer (DSSAT) crop simulation model for four major crops, run globally on a 0.5 degree grid and weighted by agricultural output under different GHG forcing scenarios using outputs from five different global climate models. Our estimates of uncertainty in agricultural technology are based on recent agro-economic 
and biophysical studies assessing the potential for closing yield gaps as well as attaining further advances in potential yields through plant breeding.

We solve the model over the period 2005-2204, with an emphasis on the first century. The model baseline accurately reflects developments in global land use over the 10 years that have already transpired, while also incorporating projections of population, income and demand growth from a variety of international agencies. The results of the perfect foresight model, based on expected realizations of climate and technological impacts on crop yields, predict a significant expansion in the area dedicated to food crops due to rapid population growth and increasing per capita demand for food at lower income levels. This expansion results in significant losses of unmanaged natural forests, while managed forest lands are little changed. This trend is reversed in the second half of the coming century due to slower population growth, and technology improvements in crop yields and food processing. The resulting crop land expansion is modest by 2100. Rising real incomes, and growing demand for timber products and ecosystem services bring a significant expansion in managed and protected natural forest land areas, which grow significantly by the end of the century. When we factor in the potential for future tipping points in agricultural productivity, due either to adverse climate impacts or barriers to further technological progress, we find relatively modest increases in cropland amounting to roughly two percent of current cropland area (30 Mha) by 2100.

\section{References}

Alexandratos, N., 2011. Critical Evaluation of Selected Projections. In: Conforti, P. (Ed.), Economic Analysis of Land Use in Global Climate Change Policy. Food and Agriculture Organization of the United Nations, Rome, pp. 465-508.

Alston, J. M., Pardey, P. G., Jan. 2014. Agricultural R\&D, Food Prices, Poverty and Malnutrition Redux. Staff Paper P14-01, University of Minnesota, Department of Applied Economics.

Bateman, I., Mace, G., Fezzi, C., Atkinson, G., Turner, K., 2011. Economic Analysis for Ecosystem Service Assessments. Environmental and Resource Economics 48 (2), 177-218.

Bellman, R., 1957. Dynamic Programming. Princeton University Press.

Benayas, J., Newton, A., Diaz, A., Bullock, J., 2009. Enhancement of Biodiversity and Ecosystem Services by Ecological Restoration: a Meta-analysis. Science 325 (5944), 1121-1124.

Bentsen, M., Bethke, I., Debernard, J., Iversen, T., Kirkevåg, A., Seland, Ø., Drange, H., Roelandt, C., Seierstad, I., Hoose, C., et al., 2012. The Norwegian Earth System Model, NorESM1-M-Part 1: Description and Basic Evaluation. Geoscientific Model Development Discussions 5, 2843-2931. 
Bouwman, A., Kram, T., Goldewijk, K., 2006. Integrated Modelling of Global Environmental Change: an Overview of Image 2.4. Tech. rep., Netherlands Environmental Assessment Agency, Bilthoven, The Netherlands.

Bulte, E., van Soest, D., Van Kooten, G., Schipper, R., 2002. Forest Conservation in Costa Rica when Nonuse Benefits are Uncertain but Rising. American Journal of Agricultural Economics 84 (1), 150-160.

Cai, Y., Judd, K. L., 2010. Stable and Efficient Computational Methods for Dynamic Programming. Journal of the European Economic Association 8 (2$3), 626-634$.

Cai, Y., Judd, K. L., Thain, G., Wright, S. J., 2013. Solving Dynamic Programming Problems on a Computational Grid. Working Paper 18714, National Bureau of Economic Research.

Cassman, K., Grassini, P., van Wart, J., 2010. Crop Yield Potential, Yield Trends, and Global Food Security in a Changing Climate. In: Hillel, D., Rosenzweig, C. (Eds.), Handbook of Climate Change and Agroecosystems. Imperial College Press, pp. 37-51.

Cassman, K. G., 1999. Ecological Intensification of Cereal Production Systems: Yield Potential, Soil Quality, and Precision Agriculture. Proceedings of the National Academy of Sciences 96 (11), 5952-5959.

Chazdon, R., 2008. Beyond Deforestation: Restoring Forests and Ecosystem Services on Degraded Lands. Science 320 (5882), 1458-1460.

Collins, W., Bellouin, N., Doutriaux-Boucher, M., Gedney, N., Hinton, T., Jones, C., Liddicoat, S., Martin, G., et al., 2008. Evaluation of the HadGEM2 Model. Hadley Center Tech. Note 74 .

Conrad, J., 1997. On the Option Value of Old-growth Forest. Ecological Economics $22(2), 97-102$.

Conrad, J., 2000. Wilderness: Options to Preserve, Extract, or Develop. Resource and Energy Economics 22 (3), 205-219.

Costanza, R., d'Arge, R., De Groot, R., Farber, S., Grasso, M., Hannon, B., Limburg, K., Naeem, S., O'Neill, R., Paruelo, J., et al., 1997. The Value of the World's Ecosystem Services and Natural Capital. Nature 387 (6630), 253-260.

Cranfield, J., Eales, J., Hertel, T., Preckel, P., 2003. Model Selection when Estimating and Predicting Consumer Demands using International, Cross Section Data. Empirical Economics 28 (2), 353-364.

Daigneault, A. J., Miranda, M. J., Sohngen, B., 2010. Optimal Forest Management with Carbon Sequestration Credits and Endogenous Fire Risk. Land Economics 86 (1), 155-172. 
Daily, G., 1997. Nature's Services: Societal Dependence on Natural Ecosystems. Island Pr.

Deaton, A., Muellbauer, J., 1980. An Almost Ideal Demand System. The American Economic Review 70 (3), 312-326.

Dufresne, J.-L., Foujols, M.-A., Denvil, S., Caubel, A., Marti, O., Aumont, O., Balkanski, Y., Bekki, S., Bellenger, H., Benshila, R., et al., 2012. Climate Change Projections using the IPSL-CM5 Earth System Model: from CMIP3 to CMIP5. Climate Dynamics, 1-43.

Dunne, J. P., John, J. G., Shevliakova, E., Stouffer, R. J., Krasting, J. P., Malyshev, S. L., Milly, P., Sentman, L. T., Adcroft, A. J., Cooke, W., et al., 2013. GFDL's ESM2 Global Coupled Climate?Carbon Earth System Models. Part II: Carbon System Formulation and Baseline Simulation Characteristics. Journal of Climate 26 (7), 2247-2267.

Elliott, J., Kelly, D., Chryssanthacopoulos, J., Glotter, M., Jhunjhnuwala, K., Best, N., Wilde, M., Foster, I., 2014. The Parallel System for Integrating Impact Models and Sectors (pSIMS). Environmental Modelling \& Software.

Evans, L., Fischer, R., 1999. Yield Potential: its Definition, Measurement, and Significance. Crop Science 39 (6), 1544-1551.

Fischer, T., Byerlee, D., Edmeades, G., 2011. Can Technology Deliver on the Yield Challenge to 2050? In: Conforti, P. (Ed.), Economic Analysis of Land Use in Global Climate Change Policy. Food and Agriculture Organization of the United Nations, Rome, pp. 389-462.

Foley, J. A., Ramankutty, N., Brauman, K. A., Cassidy, E. S., Gerber, J. S., Johnston, M., Mueller, N. D., O'Connell, C., Ray, D. K., West, P. C., et al., 2011. Solutions for a Cultivated Planet. Nature 478 (7369), 337-342.

Golub, A., Hertel, T., Sohngen, B., 2009. Land Use Modeling in RecursivelyDynamic GTAP Framework. In: Hertel, T., Rose, S., Tol, R. (Eds.), Economic Analysis of Land Use in Global Climate Change Policy. Routledge, pp. 235278.

Grassini, P., Eskridge, K. M., Cassman, K. G., 2013. Distinguishing between Yield Advances and Yield Plateaus in Historical Crop Production Trends. Nature Communications 4.

Gurgel, A., Reilly, J., Paltsev, S., 2007. Potential Land Use Implications of a Global Biofuels Industry. Journal of Agricultural \& Food Industrial Organization 5 (2), 1-34.

Hanoch, G., 1975. Production and Demand Models with Direct or Indirect Implicit Additivity. Econometrica 43 (3), 395-419. 
Hertel, T. W., 2011. The Global Supply and Demand for Agricultural Land in 2050: A Perfect Storm in the Making? American Journal of Agricultural Economics 93 (2), 259-275.

Hertel, T. W., Burke, M. B., Lobell, D. B., 2010c. The Poverty Implications of Climate-Induced Crop Yield Changes by 2030. Global Environmental Change 20 (4), 577-585.

Hocking, M., Stolton, S., Dudley, N., 2000. Evaluating Effectiveness: A Framework for Assessing the Management of Protected Areas. IUCN, Gland, Switzerland, and Cambridge, UK.

IPCC, 2014. Climate Change 2014: Impacts, Adaptation and Vulnerability: Contribution of Working Group II to the Fifth Assessment Report of the Intergovernmental Panel on Climate Change. Cambridge University Press.

Jones, J. W., Hoogenboom, G., Porter, C., Boote, K., Batchelor, W., Hunt, L., Wilkens, P., Singh, U., Gijsman, A., Ritchie, J., 2003. The DSSAT Cropping System Model. European Journal of Agronomy 18 (3), 235-265.

Leroux, A., Martin, V., Goeschl, T., 2009. Optimal Conservation, Extinction Debt, and the Augmented Quasi-option Value. Journal of Environmental Economics and Management 58 (1), 43-57.

Licker, R., Johnston, M., Foley, J. A., Barford, C., Kucharik, C. J., Monfreda, C., Ramankutty, N., 2010. Mind the Gap: How do Climate and Agricultural Management Explain the 'Yield Gap' of Croplands around the World? Global Ecology and Biogeography 19 (6), 769-782.

Lobell, D., Schlenker, W., Costa-Roberts, J., 2011. Climate Trends and Global Crop Production Since 1980. Science 333 (6042), 616-620.

Lobell, D. B., Cassman, K. G., Field, C. B., 2009. Crop Yield Gaps: their Importance, Magnitudes, and Causes. Annual Review of Environment and Resources 34 (1), 179.

Long, S., 1991. Modification of the Response of Photosynthetic Productivity to Rising Temperature by Atmospheric CO2 Concentrations: Has its Importance been Underestimated? Plant, Cell \& Environment 14 (8), 729-739.

Long, S. P., Ainsworth, E. A., Leakey, A. D., Nösberger, J., Ort, D. R., 2006. Food for Thought: Lower-Than-Expected Crop Yield Stimulation with Rising CO2 Concentrations. Science 312 (5782), 1918-1921.

Moss, R. H., Babiker, M., Brinkman, S., Calvo, E., Carter, T., Edmonds, J. A., Elgizouli, I., Emori, S., Lin, E., Hibbard, K., et al., 2008. Towards New Scenarios for Analysis of Emissions, Climate Change, Impacts, and Response Strategies. Tech. Rep. PNNL-SA-63186, Pacific Northwest National Laboratory (PNNL), Richland, WA (US). 
National Research Council, 2005. Valuing Ecosysten Services: Toward Better Eenvironmental Ddecision-Making. National Academies Press.

Nesshöver, C., Aronson, J., Blignaut, J., Lehr, D., Vakrou, A., Wittmer, H., 2009. Investing in Ecological Infrastructure. In: ten Brink, P. (Ed.), The Economics of Ecosystems and Biodiversity: National and International Policy Making. An Output of TEEB. Earthscan, pp. 401-448.

Paltsev, S., Reilly, J., Jacoby, H., Eckaus, R., McFarland, J., Sarofim, M., Asadoorian, M., Babiker, M., 2005. The MIT Emissions Prediction and Policy Analysis (EPPA) Model: Version 4. Tech. rep., MIT Joint Program on the Science and Policy of Global Change.

Parry, M. L., Rosenzweig, C., Iglesias, A., Livermore, M., Fischer, G., 2004. Effects of Climate Change on Global Food Production under SRES Emissions and Socio-Economic Scenarios. Global Environmental Change 14 (1), 53-67.

Reilly, J., Paltsev, S., Felzer, B., Wang, X., Kicklighter, D., Melillo, J., Prinn, R., Sarofim, M., Sokolov, A., Wang, C., 2007. Global Economic Effects of Changes in Crops, Pasture, and Forests due to Changing Climate, Carbon Dioxide, and Ozone. Energy Policy 35 (11), 5370-5383.

Richards, K., Stokes, C., 2004. A Review of Forest Carbon Sequestration Cost Studies: A Dozen Years of Research. Climatic Change 63 (1), 1-48.

Rimmer, M., Powell, A., 1996. An Implicitly Additive Demand System. Applied Economics 28 (12), 1613-1622.

Rosenzweig, C., Elliott, J., Deryng, D., Ruane, A., Arneth, A., Bootef, K., Folberth, C., Glotter, M., Khabarov, N., Müller, C., Neumann, K., Piontek, F., Pugh, T., Schmid, E., Stehfest, E., Jones, J., 2014. Assessing Agricultural Risks of Climate Change in the 21st Century in a Global Gridded Crop Model Intercomparison. Proceedings of the National Academy of Sciences 111 (9), $3268-3273$.

Searchinger, T., Heimlich, R., Houghton, R., Dong, F., Elobeid, A., Fabiosa, J., Tokgoz, S., Hayes, D., Yu, T., 2008. Use of US Croplands for Biofuels Increases Greenhouse Gases through Emissions from Land-Use Change. Science 319 (5867), 1238.

Sohngen, B., Mendelsohn, R., 2003. An Optimal Control Model of Forest Carbon Sequestration. American Journal of Agricultural Economics 85 (2), 448-457.

Sohngen, B., Mendelsohn, R., 2007. A Sensitivity Analysis of Forest Carbon Sequestration. In: Schlesinger, M. (Ed.), Human-Induced Climate Change: An Interdisciplinary Assessment. Cambridge University Press, pp. 227-237.

Sorrell, S., Dimitropoulos, J., 2008. The Rebound Effect: Microeconomic Definitions, Limitations and Extensions. Ecological Economics 65 (3), 636-649. 
Stavins, R., 1999. The Costs of Carbon Sequestration: A Revealed-preference Approach. The American Economic Review 89 (4), 994-1009.

Steinbuks, J., Hertel, T. W., 2013. Energy Prices Will Play an Important Role in Determining Global Land Use in the Twenty First Century. Environmental Research Letters 8 (1), 014014.

Watanabe, S., Hajima, T., Sudo, K., Nagashima, T., Takemura, T., Okajima, H., Nozawa, T., Kawase, H., Abe, M., Yokohata, T., et al., 2011. MIROCESM 2010: Model Description and Basic Results of CMIP5-20c3m Experiments. Geoscientific Model Development 4, 845-872.

Wise, M., Calvin, K., 2011. GCAM 3.0 Agriculture and Land Use: Technical Description of Modeling Approach. Tech. rep., Pacific Northwest National Laboratory (PNNL), Richland, WA (US).

Wise, M., Calvin, K., Thomson, A., Clarke, L., Bond-Lamberty, B., Sands, R., Smith, S., Janetos, A., Edmonds, J., 2009. Implications of Limiting CO2 Concentrations for Land Use and Energy. Science 324 (5931), 1183.

Yu, W., Hertel, T., Preckel, P., Eales, J., 2004. Projecting World Food Demand Using Alternative Demand Systems. Economic Modelling 21 (1), 99-129. 


\section{Technical Appendix}

\section{A.1 Model Equations, Variables and Parameters}

\section{Equations}

Land Use

$$
\begin{gathered}
L=\sum_{i=A, C, N, R} L_{t}^{i} \\
L_{t}^{N}=L_{t+1}^{N}-\Delta_{t}^{N, A}-\Delta_{t}^{N, R} \\
L_{t+1}^{R}=L_{t}^{R}+\Delta_{t}^{N, R} \\
L_{t+1}^{A}=L_{t}^{A}+\Delta_{t}^{N, A}+\Delta_{t}^{C, A} \\
L_{t+1}^{C}=L_{t}^{C}-\Delta_{t}^{C, A} \\
L_{t}^{C}=\sum_{v=1}^{v_{\max }} L_{v, t}^{C} \\
L_{v+1, t+1}^{C}=L_{v, t}^{C}-\Delta_{v, t}^{C, H}, \quad v<v_{\max }-1 \\
L_{v_{\max }, t+1}^{C}=L_{v_{\max }, t}^{C}-\Delta_{v_{\max }, t}^{C, H}+L_{v_{\max }-1, t}^{C}-\Delta_{v_{\max }-1, t}^{C, H} \\
L_{1, t+1}^{C}=\Delta_{t}^{C, C}
\end{gathered}
$$

Fossil Fuels

$$
X_{t+1}^{F}=X_{t}^{F}-\Delta_{t}^{F, E}-\Delta_{t}^{F, n}+\Delta_{t}^{F, D}
$$

Other Primary Resources

$$
X_{t+1}^{O}=\kappa^{o, X} X_{t}^{O}
$$

Intermediate Products

$$
\begin{aligned}
& x_{t}^{p}=\theta_{t}^{p} \Delta_{t}^{F, E} \\
& x_{t}^{n}=\theta^{n} \Delta_{t}^{F, n}
\end{aligned}
$$




$$
\begin{gathered}
x_{t}^{c}=\theta_{t}^{c}\left(\alpha^{n}\left(L_{t}^{A}\right)^{\rho_{n}}+\left(1-\alpha^{n}\right)\left(x_{t}^{n}\right)^{\rho_{n}}\right)^{\frac{1}{\rho_{n}}} \\
x_{t}^{b}=\theta^{b} x_{t}^{c, b} \\
x_{t}^{w}=\sum_{v=1}^{v_{\max }} \theta_{v, t}^{w} \Delta_{v, t}^{C, H}
\end{gathered}
$$

Final Goods and Services

$$
\begin{gathered}
Y_{t}^{f}=\theta_{t}^{f}\left(x^{c}-x^{c, b}\right) \\
Y_{t}^{e}=\theta_{t}^{e}\left(\alpha^{e}\left(x_{t}^{b}\right)^{\rho_{e}}+\left(1-\alpha^{e}\right)\left(x_{t}^{p}\right)^{\rho_{e}}\right)^{\frac{1}{\rho_{e}}} \\
Y_{t}^{w}=\theta_{t}^{s} x_{t}^{w} \\
Y_{t}^{r}=\theta^{r}\left[\begin{array}{c}
\alpha^{A, r}\left(L_{t}^{A}\right)^{\rho_{r}}+\alpha^{C, r}\left(L_{t}^{C}\right)^{\rho_{r}} \\
+\left(1-\alpha^{A, r}-\alpha^{C, r}\right)\left(L_{t}^{N}+\theta^{R} L_{t}^{R}\right)^{\rho_{r}}
\end{array}\right] \\
Y_{t}^{o}=\theta_{t}^{o}\left[\begin{array}{c}
\frac{1}{\rho_{r}} \\
X_{t}^{O}-c^{o, c} \frac{x_{t}^{c}}{\theta_{t}^{c}}-c^{o, f} \frac{Y_{t}^{f}}{\theta_{t}^{f}}-c^{o, p} x_{t}^{p}-c^{o, n} x_{t}^{n} \\
-c^{o, b} x_{t}^{b}-c_{t}^{o, w} \Delta_{t}^{C, H}-c^{o, s} x_{t}^{w}-c^{o, r} L_{t}^{R} \\
-c^{p} \Delta_{t}^{C, C}-c_{t}^{N}-c_{t}^{R}-c_{t}^{F}-c_{t}^{H}
\end{array}\right]
\end{gathered}
$$

Technology

$$
\begin{gathered}
\theta_{t}^{c}=\frac{\theta_{T}^{c} \theta_{0}^{c} e^{\kappa_{c} t}}{\theta_{T}^{c}+\theta_{0}^{c}\left(e^{\kappa_{c} t}-1\right)} \\
\theta_{v, t}^{w}=\left\{\begin{array}{c}
0.00001 \text { if } v \leq \underline{v} \\
\bar{\theta}_{v}^{w}\left(1+\kappa_{v}^{w} t\right) \text { if } v>\underline{v} \quad, \bar{\theta}_{v}^{w}=\exp \left(\psi_{a}-\frac{\psi_{b}}{(v-\underline{v})}\right) \\
\theta_{t}^{i}=\theta_{0}^{i}\left(1+\kappa^{i}\right)^{t}, i=f, e, s, o
\end{array}\right.
\end{gathered}
$$

Costs

$$
\begin{gathered}
c_{t}^{N}=\xi_{0}^{n}\left(\Delta_{t}^{N, A}+\Delta_{t}^{N, R}\right)+\xi_{1}^{n}\left(\Delta_{t}^{N, A}+\Delta_{t}^{N, R}\right)^{2} \\
c_{t}^{R}=\xi_{0}^{R} \Delta_{t}^{N, R}+\xi_{1}^{R}\left(\Delta_{t}^{N, R}\right)^{2}
\end{gathered}
$$




$$
\begin{gathered}
c_{t}^{F}=\xi_{1}^{P}\left(\Delta_{t}^{F, E}+\Delta_{t}^{F, n}\right)^{2}\left(\frac{X_{0}^{F}+\Delta^{F, D}}{X_{t}^{F}+\Delta^{F, D}}\right) \\
c_{t}^{H}=\xi_{1}^{H}\left(\Delta_{t}^{C, H}-\Delta_{t}^{C, C}\right)^{2}+\sum_{v} \frac{\xi_{2}^{H}}{L_{v, t+1}^{C}+\xi_{2}^{H}}
\end{gathered}
$$

Preferences

$$
\begin{gathered}
U\left(\overrightarrow{y_{t}}\right)=\frac{\left(u\left(\overrightarrow{y_{t}}\right)\right)^{1-\gamma}}{1-\gamma} \Pi_{t}, \quad \overrightarrow{y_{t}}=\left(Y_{t}^{f}, Y_{t}^{e}, Y_{t}^{w}, Y_{t}^{r}, Y_{t}^{o}\right) / \Pi_{t} \\
u\left(\overrightarrow{y_{t}}\right)=\exp \left[\sum_{q=f, e, w, r, o}\left(\frac{\alpha_{q}+\beta_{q} \exp \left(u\left(\overrightarrow{y_{t}}\right)\right)}{1+\exp \left(u\left(\overrightarrow{y_{t}}\right)\right)}\right) \log \left(y_{t}^{q}-\underline{y}^{q}\right)\right]
\end{gathered}
$$

Population

$$
\Pi_{t}=\frac{\Pi_{T} \Pi_{0} e^{\kappa^{\pi} t}}{\Pi_{T}+\Pi_{0}\left(e^{\kappa^{\pi} t}-1\right)}
$$

Welfare

$$
\Omega=\sum_{t=0}^{T-1} \delta^{t} \mathbb{E}\left\{U\left(\overrightarrow{y_{t}}\right)\right\}+\delta^{T} \mathbb{E}\left\{\Gamma\left(L_{T}^{U}, L_{T}^{C}\right)\right\}
$$


Table A.1: Model Exogenous Variables

\begin{tabular}{lll}
\hline Parameter & Description & Units \\
\hline & & \\
Exogenous & Variables & \\
$\Delta_{t}^{F, D}$ & Flow of Newly Discovered Fossil Fuels & trillion toe \\
$X_{t}^{O}$ & Other Primary Goods & trillion USD \\
$\theta_{t}^{c}$ & Crop Productivity Index & tons per Ha \\
$\theta_{v, t}^{w}$ & Logging Productivity Index & tons per Ha \\
$\theta_{t}^{f}$ & Food Processing Productivity Index & \\
$\theta_{t}^{e}$ & Energy Efficiency Index & \\
$\theta_{t}^{s}$ & Wood Processing Productivity Index & \\
$\theta_{t}^{o}$ & Total Factor Productivity Index & \\
$C_{t}^{N}$ & Natural Land Access Cost & share of $X_{t}^{O}$ \\
$C_{t}^{R}$ & Natural Land Protection Cost & share of $X_{t}^{O}$ \\
$C_{t}^{H}$ & Managed Forest Conversion Cost & share of $X_{t}^{O}$ \\
$C_{t}^{F}$ & Fossil Fuel Extraction Cost & share of $X_{t}^{O}$ \\
$\Pi_{t}$ & Population & billion people \\
\hline
\end{tabular}


Table A.2: Model Endogenous Variables

\begin{tabular}{lll}
\hline Parameter & Description & Units \\
\hline$L_{t}^{A}$ & Agricultural Land Area & \\
$L_{t}^{C}$ & Commercial Forest Land Area & GHa \\
$L_{t}^{N}$ & Unmanaged Natural Lands & GHa \\
$\Delta L_{t}^{N, A}$ & Flow of Deforested Natural Lands & GHa \\
$L_{t}^{R}$ & Protected Natural Lands & GHa \\
$\Delta L_{t}^{N, R}$ & Flow of Protected Natural Lands & GHa \\
$\Delta L_{t}^{C, A}$ & Flow of Managed Forest Land to Agriculture & GHa \\
$\Delta L_{t}^{C, C}$ & Replanted Forest Land Area & GHa \\
$\Delta L_{v, H}^{C, H}$ & Harvested Forest Land Area of Vintage $v$ & GHa \\
$X_{t}^{F}$ & Stock of Fossil Fuels & Ttoe \\
$\Delta_{t}^{F, E}$ & Flow of Fossil Fuels Converted to Petroleum & Ttoe \\
$\Delta_{t}^{F, n}$ & Flow of Fossil Fuels Converted to Fertilizers & Ttoe \\
$x_{t}^{p}$ & Petroleum Products & Gtoe \\
$x_{t}^{n}$ & Fertlizers & Gton \\
$x_{t}^{c}$ & Food Crops & Gton \\
$x_{t}^{b}$ & Biofuels & Gtoe \\
$x_{t}^{w}$ & Raw Timber & Gton \\
$Y_{t}^{f}$ & Services from Processed Food & billion USD \\
$Y_{t}^{e}$ & Energy Services & billion USD \\
$Y_{t}^{w}$ & Services from Processed Timber & billion USD \\
$Y_{t}^{r}$ & Eco-system Services & billion USD \\
$Y_{t}^{o}$ & Other Goods and Services & trillion USD \\
\hline & &
\end{tabular}


Table A.3: Baseline Parameters

\begin{tabular}{llll}
\hline Parameter & Description & Units & Value \\
\hline Population & & & \\
& & & \\
$\Pi_{0}$ & Population in 2004 & billion people & 6.39 \\
$\Pi_{T}$ & Population in time T & billion people & 10.1 \\
$\kappa^{\pi}$ & Population Convergence Rate & & 0.042
\end{tabular}

Land Use

$L \quad$ Total Land Area

$L_{0}^{A} \quad$ Area of Agricultural Land in 2004

$L_{0}^{C} \quad$ Area of Commercial Forest Land in 2004

$L_{0}^{N} \quad$ Area of Unmanaged Natural Land in 2004

$L_{0}^{R} \quad$ Area of Protected Natural Land in 2004

$\xi_{0}^{n} \quad$ Access Cost Function Parameter

$\xi_{1}^{n} \quad$ Access Cost Function Parameter

$\xi_{0}^{R} \quad$ Protection Cost Function Parameter

$\xi_{1}^{R} \quad$ Protection Cost Function Parameter

Fossil Fuels

$X_{0}^{F}$

$\Delta^{F, D}$

$\xi_{1}^{P}$

Endowment of Fossil fuels in 2004

Flow of Newly Discovered Fossil Fuels

Fuel Extraction Cost Function Parameter

Other Primary Goods

$X_{0}^{O} \quad$ Endowment of Other Primary Goods in 2004

$\kappa^{o, X}$

Growth Rate of Other Primary Goods

Intermediate Products

$\theta^{p} \quad$ Petroleum Conversion Factor

$c^{o, p} \quad$ Petroleum Conversion Cost

$\theta^{n} \quad$ Fertilizer Conversion Factor

$c^{o, n} \quad$ Fertilizer Conversion Cost

$\theta^{b} \quad$ Biofuels Conversion Rate

$c^{o, b} \quad$ Biofuels Conversion Cost billion $\mathrm{Ha}$

5.83

billion $\mathrm{Ha}$

1.53

billion $\mathrm{Ha}$

1.62

billion $\mathrm{Ha}$

2.47

billion $\mathrm{Ha}$

0.207

0.216

43

2.43

215.7

trillion toe

0.343

trillion toe

0.008

1079

$\mathrm{USD} \times 10^{13}$

3.274

Billion ton

0.0035

Gtoe / Ttoe

500

share of $X_{t}^{O} \quad 0.0023$

Gton / Ttoe 1071

share of $X_{t}^{O} \quad 0.073$

toe/ton

0.283

share of $X_{t}^{O} \quad 0.001$ 
Table A.3: Baseline Parameters (continued)

\begin{tabular}{|c|c|c|c|}
\hline Parameter & Description & Units & Value \\
\hline$a^{n}$ & Share of Agricultural Land in CES function & & 0.55 \\
\hline$\rho_{n}$ & $\begin{array}{l}\text { CES Parameter for Agricultural Land and } \\
\text { Fertilizers }\end{array}$ & & 0.123 \\
\hline$\theta_{0}^{c}$ & Crop Technology Index in 2004 & tons per $\mathrm{Ha}$ & 4.89 \\
\hline$\theta_{T}^{c}$ & Crop Technology Index in 2100 & tons per $\mathrm{Ha}$ & 8.8 \\
\hline$\kappa^{c}$ & Convergence Rate of Crop Technology Index & & 0.025 \\
\hline$c^{o, c}$ & Crop Breeding Cost & share of $X_{t}^{O}$ & 0.0069 \\
\hline$\psi_{a}$ & Merchantable Timber Yield Parameter 1 & & 6.58 \\
\hline$\psi_{b}$ & Merchantable Timber Yield Parameter 2 & & 76.5 \\
\hline $\bar{v}$ & Minimum Age for Merchantable Timber & Years & 11 \\
\hline$\kappa_{v}^{w}$ & Timber Yield Gains of Vintage $v$ & Share of Yield 0 & 0.011 \\
\hline$c^{p}$ & Forest Planting Cost & share of $X_{t}^{O}$ & 0.00005 \\
\hline$c^{o, w}$ & Forest Harvesting Cost & share of $X_{t}^{O}$ & 0.0012 \\
\hline$\xi_{1}^{H}$ & Forest Conversion Adjustment Cost Parameter & & 43 \\
\hline$\xi_{2}^{H}$ & Forest Conversion Adjustment Cost Parameter & & 0.0005 \\
\hline \multicolumn{4}{|c|}{ Final Goods and Services } \\
\hline$\theta_{0}^{f}$ & Food Processing Technology Index in 2004 & & 1.5 \\
\hline$\kappa^{f}$ & $\begin{array}{l}\text { Food Processing Technology Index Growth } \\
\text { Rate }\end{array}$ & & 0.0225 \\
\hline$c^{o, f}$ & Food Processing Cost & share of $X_{t}^{O}$ & 0.0043 \\
\hline$\theta_{0}^{e}$ & Energy Efficiency Index in 2004 & & 1.195 \\
\hline$\kappa^{e}$ & Energy Efficiency Index Growth Rate & & 0.0225 \\
\hline$\rho_{e}$ & $\begin{array}{l}\text { CES Parameter for Drop-in Fuels and } 1 \mathrm{G} \\
\text { Biofuels }\end{array}$ & & 0.5 \\
\hline$\alpha^{e}$ & Share of Biofuels in CES Function & & 0.09 \\
\hline$\theta_{0}^{s}$ & Timber Processing Technology Index in 2004 & & 1.52 \\
\hline$\kappa^{s}$ & Timber Processing Technology Growth Rate & & 0.0225 \\
\hline$c^{o, s}$ & Timber Processing Cost & share of $X_{t}^{O}$ & 0.0626 \\
\hline$\theta^{r}$ & Ecosystem Services Technology Index & & 0.64 \\
\hline$\alpha^{C, r}$ & Share of Agricultural Land in CES Function & & 0.07 \\
\hline$\alpha^{F, r}$ & $\begin{array}{l}\text { Share of Managed Forest Lands in CES } \\
\text { Function }\end{array}$ & & 0.34 \\
\hline$\rho_{r}$ & CES Parameter for Ecosystem Services & & 0.123 \\
\hline$\theta^{R}$ & Effectiveness Index of Protected Lands & & 10 \\
\hline$c^{o, r}$ & Cost of Ecosystem Services & share of $X_{t}^{O}$ & 0.0020 \\
\hline$\theta_{0}^{o}$ & Total factor Productivity Index in 2004 & & 1.854 \\
\hline$\kappa^{o}$ & Total Factor Index Growth Rate & & 0.0225 \\
\hline
\end{tabular}


Table A.3: Baseline Parameters (continued)

\begin{tabular}{|c|c|c|c|}
\hline Parameter & Description & Units & Value \\
\hline \multicolumn{4}{|c|}{ Preferences and Welfare } \\
\hline$\alpha_{f}$ & $\begin{array}{l}\text { AIDADS Marginal Budget Share at Subsistence } \\
\text { Income for Services from Processed Food }\end{array}$ & & 0.2 \\
\hline$\alpha_{e}$ & $\begin{array}{l}\text { AIDADS Marginal Budget Share at Subsistence } \\
\text { Income for Energy Services }\end{array}$ & & 0.13 \\
\hline$\alpha_{w}$ & $\begin{array}{l}\text { AIDADS Marginal Budget Share at Subsistence } \\
\text { Income for Services from Processed Timber }\end{array}$ & & 0.136 \\
\hline$\alpha_{r}$ & $\begin{array}{l}\text { AIDADS Marginal Budget Share at Subsistence } \\
\text { Income for Ecosystem Services }\end{array}$ & & 0.012 \\
\hline$\alpha_{o}$ & $\begin{array}{l}\text { AIDADS Marginal Budget Share at Subsistence } \\
\text { Income for Other Goods and Services }\end{array}$ & & 0.522 \\
\hline$\beta_{f}$ & $\begin{array}{l}\text { AIDADS Marginal Budget Share at High } \\
\text { Income for Services from Processed Food }\end{array}$ & & 0.034 \\
\hline$\beta_{e}$ & $\begin{array}{l}\text { AIDADS Marginal Budget Share at High } \\
\text { Income for Energy Services }\end{array}$ & & 0.065 \\
\hline$\beta_{w}$ & $\begin{array}{l}\text { AIDADS Marginal Budget Share at High } \\
\text { Income for Services from Processed Timber }\end{array}$ & & 0.092 \\
\hline$\beta_{r}$ & $\begin{array}{l}\text { AIDADS Marginal Budget Share at High } \\
\text { Income for Ecosystem Services }\end{array}$ & & 0.042 \\
\hline$\beta_{o}$ & $\begin{array}{l}\text { AIDADS Marginal Budget Share at High } \\
\text { Income for Other Goods and Services }\end{array}$ & & 0.767 \\
\hline$\gamma^{g}$ & $\begin{array}{l}\text { AIDADS Subsistence Parameter for Processed } \\
\text { Grain Products }\end{array}$ & & 0.1 \\
\hline$\gamma^{e}$ & $\begin{array}{l}\text { AIDADS Subsistence Parameter for Energy } \\
\text { Services }\end{array}$ & & 0.01 \\
\hline$\gamma^{w}$ & $\begin{array}{l}\text { AIDADS Subsistence Parameter for Processed } \\
\text { Timber Products }\end{array}$ & & 0.1 \\
\hline$\gamma^{r}$ & $\begin{array}{l}\text { AIDADS Subsistence Parameter for Ecosystem } \\
\text { Services }\end{array}$ & & 0.1 \\
\hline$\gamma^{o}$ & $\begin{array}{l}\text { AIDADS Subsistence Parameter For Other } \\
\text { Goods and Services }\end{array}$ & & 0.1 \\
\hline$\gamma$ & Risk Aversion Parameter & & 2 \\
\hline$\delta$ & Social Discount Rate & & 0.95 \\
\hline
\end{tabular}




\section{B.1 Baseline Construction}

The model baseline extends for a period of 200 years, with an emphasis on the first century, and the starting point being the world economy in 2004. It is consistent with the IPCC (2000) A1B climate change scenario's storyline that describes a future world of strong economic growth, global population that grows quickly until mid-century and slows thereafter, the rapid introduction of new and more efficient technologies, and balanced energy use across all sources. It also foresees that, as the economy grows, its economic structure changes toward a service economy, including the expansion of ecosystem services sector. The majority of model's baseline parameters are based on the Global Trade Analysis Project (GTAP) v.7 data base (Hertel 1997, Narayanan and Walmsley 2008) and its satellite data for land use and global climate change policy (Hertel et al. 2009). The values of other model parameters come from variety of the international or government agencies (United Nations, FAO, U.S. Energy Information Administration) and economic, agronomic and environmental science literatures. The values of baseline parameters are summarized in Table A.3 and Figure B.1.

\section{B.1.1 Primary Resources}

\section{B.1.1.1 Land}

The data for land endowments come from the GTAP Integrated Global Land Use Data Base (Lee et al. 2009) and GTAP Global Forestry Data Base (Sohngen et al. 2009b). We define the managed lands as the sum of crop land and accessible forest land areas. The natural land is defined as inaccessible forest land. Other land areas, such as built-up lands, pastures, grasslands, savannah, shrublands, desserts, and barren lands, are not included in the current version

of the model. The data for initial allocation of unmanaged natural lands come from Antoine et al. (2008, p.8, Table 3).

We assume that marginal access cost per hectare, $c_{t}^{N}$, is a quadratic function of converted natural land:

$$
c_{t}^{N}=\xi_{0}^{n}\left(\Delta_{t}^{N, A}+\Delta_{t}^{N, R}\right)+\xi_{1}^{n}\left(\Delta_{t}^{N, A}+\Delta_{t}^{N, R}\right)^{2} .
$$

In equation (B.1), the parameter $\xi_{0}^{n}$ determines the long-run natural land access costs with respect to accessed hectares. The parameter $\xi_{2}^{n}$ governs the size 

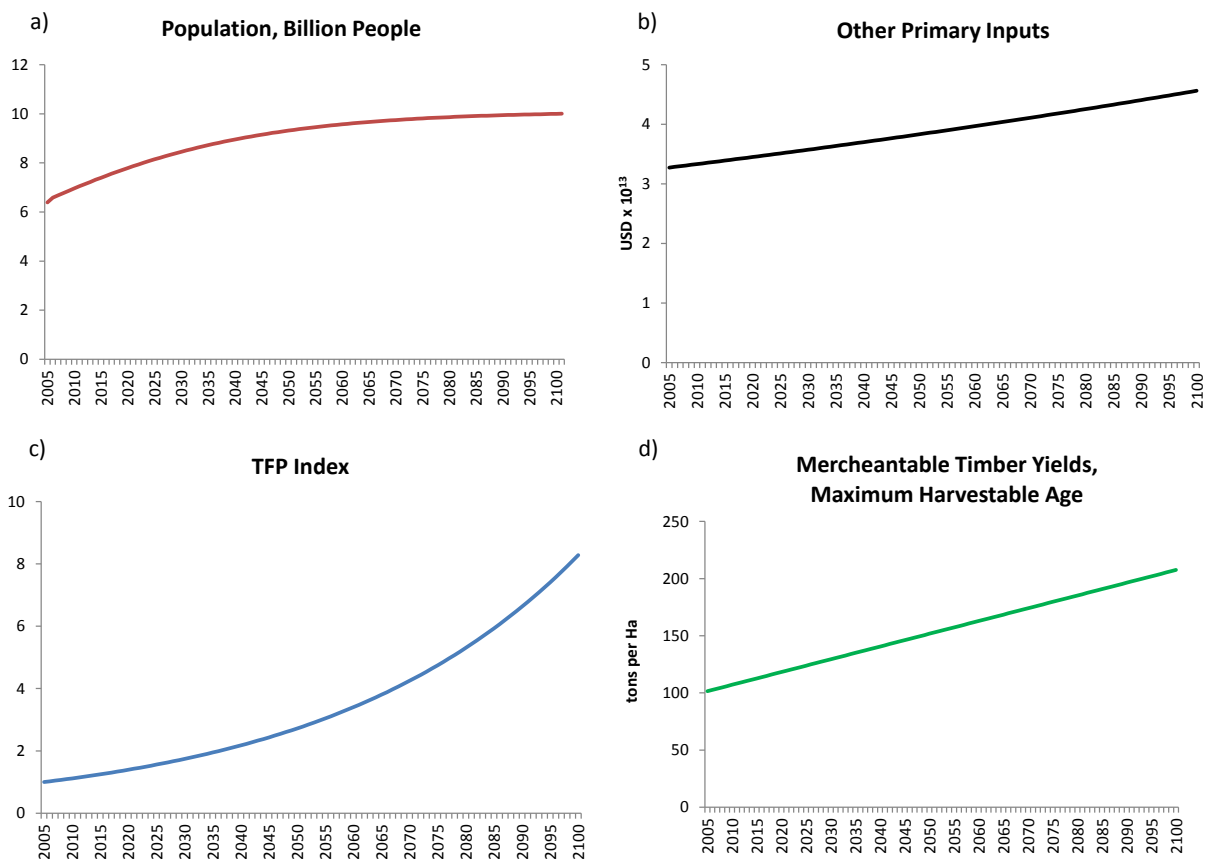

Figure B.1: Projections of Exogenous Variables, 2005-2104 
of the short-term adjustment costs. Natural land protection costs per hectare are also assumed a quadratic function of protected natural land:

$$
c_{t}^{R}=\xi_{0}^{R} \Delta_{t}^{N, R}+\xi_{1}^{R}\left(\Delta_{t}^{N, R}\right)^{2} .
$$

In equation (B.2), the parameter $\xi_{0}^{R}$ determines the long-run costs of protecting land. The parameter $\xi_{1}^{R}$ captures the short-term adjustment costs. The parameter values defining natural land access cost function (B.1), and natural land protection cost function (B.2) are calibrated based on FAO (2010) data to match deforestation rates in 2004 and ensure stable rates of natural land access and protection.

\section{Managed forests}

We set the number of forest tree vintages to 50 and assume that average densities of managed forest land corresponding to different tree ages are uniformly distributed.

\section{B.1.1.2 Fossil Fuels}

The primary fossil fuels linked to the economic analysis of land use are petroleum products and natural gas. Biofuels substitute for petroleum products and, to lesser extent, natural gas, in energy demand for transportation services. The natural gas is also the key input in nitrogen fertilizers' production. To determine the amount of newly discovered oil and gas reserves, $\Delta_{t}^{F, D}$ we estimate different econometric specifications based on historical data from the BP Statistical Review of World Energy database $(2013)^{1}$ globally over the period of 1980 - 2010. We find that newly discovered oil and gas reserves exhibit a linear trend, adding a constant amount across time, i.e., $\Delta_{t}^{F, D}=\Delta^{F, D}$.

As petroleum products' and natural gas prices are closely related in the long run (Hartley et al. 2008), we use the same cost function for both types of fossil fuels. Specifically, we assume that the cost of fossil fuels is a nonlinear quadratic function with accelerating costs as the stock of fossil fuels depletes (Nordhaus and Boyer 2000):

$$
c_{t}^{F}=\xi_{1}^{P}\left(\Delta_{t}^{F, E}+\Delta_{t}^{F, n}\right)^{2}\left(\frac{X_{0}^{F}+\Delta_{t}^{F, D}}{X_{t}^{F}+\Delta_{t}^{F, D}}\right),
$$

\footnotetext{
${ }^{1}$ The database can be accessed online at http://www.bp.com/en/global/corporate/ about-bp/energy-economics/statistical-review-of-world-energy-2013.html
} 
where the parameter $\xi_{1}^{P}$ captures the curvature of the liquid fossil fuel cost function. We calibrate the values of the parameter $\xi_{1}^{P}$ to match observed extraction rates of oil and natural gas in the first decade of the 21st century. We obtain the extraction quantities of oil and natural gas from the BP Statistical Review of World Energy database (2013).

\section{B.1.1.3 Other Primary Resources}

The initial values for the production of other primary inputs come from GTAP v.7 database and are defined as the value of output from labor (skilled and unskilled), capital, and natural resources. We set the growth rate of other primary resources as the difference between global GDP growth and total factor productivity growth rates from Jorgenson and $\mathrm{Vu}$ (2010) projections based on econometric estimates for 122 economies over the 1990 - 2008 period (see Figure B.1, panel b).

\section{B.1.2 Intermediate Inputs}

\section{B.1.2.1 Petroleum Products}

The refining of petroleum, $x_{t}^{p}$, is a chemical engineering process that can be described by a linear production function:

$$
x_{t}^{p}=\theta_{t}^{p} \Delta_{t}^{F, E},
$$

where $\theta^{p}$ is the rate of conversion of fossil fuels to petroleum products. We set $\theta^{p}$ based on the conversion factor supplied by the U.S. Energy Information Administration. ${ }^{2}$ We obtain the expenditures on refining fossil fuels into petroleum products from GTAP v.7 database (sectors 16, 17, and 32), and normalize them by the total expenditures on other primary resources. To compute the normalized average cost of refining fossil fuels, $c^{o, p}$, we divide normalized expenditures on the amount of petroleum products produced in 2004, which we obtain from BP Statistical Review of World Energy database (2013).

\footnotetext{
${ }^{2}$ See http: //www .eia.gov/tools/faqs/faq. $c f m ? i d=24 \& t=7$.
} 


\section{B.1.2.2 Fertilizers}

The production of fertilizers, $x_{t}^{n}$, is a chemical engineering process that can be described by a linear production function:

$$
x_{t}^{n}=\theta^{n} \Delta_{t}^{F, n},
$$

where $\theta^{n}$ is the rate of conversion of fossil fuels to fertilizers. There are three types of fertilizer used in agricultural production: nitrogen fertilizers, phosphate fertilizers, and potash fertilizers. In our model we focus on nitrogen fertilizers. These fertilizers are particularly important in the climate policy debate, because their production is the most energy- and GHG- intensive. They are also critical to boosting yields in response to scarcity of land. ${ }^{3}$ We use the FAOSTAT database $^{4}$ to obtain the global production of nitrogen fertilizers in 2004. For fertilizers' production costs and conversion rates we consider anhydrous ammonia $\left(\mathrm{NH}_{3}\right)$, which is one of the most common nitrogen fertilizers. We use USDA ERS fertilizer use and price dataset ${ }^{5}$ to obtain the fertilizers' price. We then subtract the fossil fuels' price from the fertilizers' price to obtain non-energy cost of fertilizers' production. This cost does not vary much across time because fossil fuels' and nitrogen fertilizers' prices are highly correlated and follow the same trend (USGAO 2003). To compute the normalized average cost of conversion of fossil fuels to fertilizers, $c^{o, n}$, we multiply the non-energy cost of fertilizers' production by its expenditure share in other primary resources.

\section{B.1.2.3 Crops}

The production of crops, $x^{c}$, uses agricultural land and fertilizers inputs, which are imperfect substitutes in plant breeding. The output of crops is determined by the constant elasticity of substitution (CES) function:

$$
x_{t}^{c}=\theta_{t}^{c}\left(\alpha^{n}\left(L_{t}^{A}\right)^{\rho_{n}}+\left(1-\alpha^{n}\right)\left(x_{t}^{n}\right)^{\rho_{n}}\right)^{\frac{1}{\rho_{n}}},
$$

\footnotetext{
${ }^{3}$ Note that by von Liebig's Law of the Minimum (yield is proportional to the amount of the most limiting nutrient, whichever nutrient it may be) the production of other two types of fertilizers will follow the path of nitrogen fertilizers.

${ }^{4}$ Thorough description of the FAOSTAT database is available from the following website: http://faostat.fao.org/.

${ }^{5}$ Thorough description of the dataset is available from the following website: http://www . ers.usda.gov/Data/FertilizerUse/.
} 
where $\theta_{t}^{c}$ and $\alpha^{n}$ are, respectively, the crop productivity index and the value share of land in production of crops at the benchmark time 0 . The parameter $\rho_{n}=\frac{\sigma_{n}-1}{\sigma_{n}}$ is a CES function parameter proportional to the elasticity of substitution of agricultural land for fertilizers, $\sigma^{n}$.

The amount of food crops (measured as the global physical production of agricultural crops) and global expenditures on food crops in 2004 come from the FAOSTAT database. The elasticity of substitution of nitrogen fertilizers for agricultural land is based on Hertel et al. (1996) estimates for the US corn production over the 1976-1990 period. We obtain the economic rent of global cropland from GTAP v.7 database. The values of crop technology index and shares of agricultural land and fertilizers in 2004 are calibrated from known values of agricultural output, fertilizers, and the agricultural land as described in Rutherford (2002).

We obtain the non land expenditures of producing food crops from GTAP v.7 database (sectors 1-8), and normalize them by the total expenditures on other primary resources. To compute the normalized average cost of producing food crops, $c^{o, c}$, we divide normalized expenditures on the amount of food crops produced in 2004 .

\section{B.1.2.4 Biofuels}

In the model baseline we define the first-generation biofuels as a grain-based ethanol. The production of biofuels, $x^{b}$, is a chemical engineering process that can be described by a linear production function:

$$
x_{t}^{b}=\theta^{b} x_{t}^{c, b},
$$

where $\theta^{b}$ is the rate of conversion of biofuels' $\mathrm{crops}^{c}, x^{c, b}$, to biofuels. The amount of biofuels produced in 2004 comes from BP Statistical Review of World Energy database (2013). The values for biofuels conversion rate and cost for ethanol are taken from Taheripour and Tyner (2011). Following Winston (2009) we adjust the quantity of first generation biofuels produced by 0.7 to match the energy content of liquid fossil fuels. To compute the normalized average cost of conversion of fossil fuels to fertilizers, $c^{o, b}$, we multiply the average conversion cost of biofuels by its expenditure share in other primary resources. 


\section{B.1.2.5 Raw Timber}

The production of raw timber comes from harvesting managed forest lands. A hectare of managed forest land of vintage $v$ yields $\theta_{v}^{w}$ tons of raw timber, $x_{v}^{w}$. The parameter $\theta_{v}^{w}$ is the merchantable timber yield, which is monotonically increasing in the average tree density of age $v$. Forest land becomes eligible for harvest when planted trees reach a minimum age for merchantable timber, $\underline{v}$. Managed forest areas with the average density of oldest trees $v_{\max }$ have the highest yield of $\theta_{v_{\max }}^{w}$. They do not grow further and stay until harvested. The following equation describes production of raw timber:

$$
x_{t}^{w}=\sum_{v=1}^{v_{\max }} \theta_{v, t}^{w} \Delta_{v, t}^{C, H} .
$$

Following Sohngen and Mendelsohn (2007) and Sohngen et al. (2009b) we assume that the merchantable timber yield function is given by the following equation:

$$
\theta_{v, t}^{w}=\left\{\begin{array}{l}
0.00001 \text { if } v \leq \underline{v} \\
\bar{\theta}_{v}^{w}\left(1+\kappa_{v}^{w} t\right) \text { if } v>\underline{v}
\end{array} \quad, \bar{\theta}_{v}^{w}=\exp \left(\psi_{a}-\frac{\psi_{b}}{v-\underline{v}}\right)\right.
$$

In equation (B.9), the parameters $\psi_{1}$ and $\psi_{2}$ are growth parameters determining the support and the slope of the timber yield function, and $\underline{v}$ is a minimum age for merchantable timber. To calculate the yield function (B.9) parameter $\psi_{b}$, we use well-known Faustmann theorem, which states that the optimal time to cut the forest is when the time rate of change of its value is equal to interest on the value of the forest plus the interest on the value of the land (Brazee and Mendelsohn 1990). Specifically, we solve numerically for $\psi_{b}$, assuming that the optimal time to cut the forest is when it reaches the age of the oldest tree vintage, $v_{\max }$, and the interest on the value of the forest plus the interest on the value of the land is equal to the socially optimal rate of time preference, which we discuss in section B.1.4 below. Once we obtain the value of $\psi_{b}$, we can infer the parameter $\psi_{a}$ using the data on carbon stock embodied in managed forests. Specifically we solve the following equation:

$$
\sum_{v=1}^{v_{\max }} \mu \exp \left(\psi_{a}-\frac{\psi_{b}}{v}\right) L_{v, 0}^{C}=Z^{C}
$$

where the parameters $\mu$ and $Z^{C}$ denote the stocking density and the embodied 
carbon stock in managed forests. Contrary to equation (B.9), we do not include the minimum age parameter in equation (B.10) as younger tree vintages absorb carbon without giving timber benefits (Sohngen et al. 2009a). We obtain the stocking density and the embodied carbon stock, as well as the minimum age for merchantable timber from GTAP Global Forestry Data Base (Sohngen et al. 2009b). We assume that the merchantable timber yield per hectare of forest land with the average tree age $v$ grows linearly across time, adding a constant amount of technology gain per annum (see Figure B.1, panel d):

$$
\theta_{v, t+1}^{w}=\theta_{v, t}^{w}+\kappa_{v}^{w}
$$

where the parameters $\theta_{v, 0}^{w}$ and $\kappa_{v}^{w}$ correspond to the initial levels and technology gains to the merchantable timber yield of vintage $v$. We obtain the data for yield growth in the commercial forestry sector by annualizing the difference in the average yields from global forest studies of Sedjo (1983) and Cubbage et al. (2010).

We assume that the average harvesting costs per ton of raw timber, are invariant to scale and are the same across all managed forest areas of different age. With continuous growth up to vintage $v_{\max }$, the average long-run cost of harvesting per hectare of managed forest land, $c^{o, w}$, is therefore a declining function of timber output. The average planting costs per hectare of newly forest planted, are invariant to scale and are the same across all vintages. We obtain the average harvesting and replanting costs from GTAP Global Forestry Data Base (Sohngen et al. 2009b). To compute the normalized average costs of replanting, $c^{p}$, and harvesting, $c^{o, n}$, we multiply corresponding average costs by their expenditure shares in other primary resources.

Harvest of managed forests and conversion of harvested forest land to agricultural land is subject to additional near term adjustment costs, $c^{H}$. Forest harvesting costs are given by

$$
c_{t}^{H}=\xi_{1}^{H}\left(\Delta_{t}^{C, H}-\Delta_{t}^{C, C}\right)^{2}+\sum_{v} \frac{\xi_{2}^{H}}{L_{v, t+1}^{C}+\xi_{2}^{H}},
$$

where the parameters $\xi_{1}^{w}$ and $\xi_{2}^{w}$ correspond to short-run adjustment costs of harvesting and rotation. We calibrate these short-run adjustment costs to match recent global trends in commercial forestry (FAO 2010). 


\section{B.1.3 Final Goods and Services}

We assume that technology indices in food and timber processing, energy, and other goods and services sector is described by the following equation:

$$
\theta_{t}^{i}=\theta_{0}^{i}\left(1+\kappa^{i}\right)^{t}, i=f, e, s, o,
$$

where the parameters $\theta_{0}^{i}$ and $\kappa^{i}$ reflect the initial level and annual growth rate in technologies of these sectors. We assume that the technology growth rates are the same across these sectors and are equal to the global economy's total factor productivity growth rate, $\kappa^{o}$.

\section{B.1.3.1 Processed Food}

We calculate the level of technology index of the food processing in 2004 using GTAP v.7 database, by dividing the output of services from processed grains and crops (GTAP sectors 21, 23-25) by the output of grains and cereals (GTAP sectors 1-8). We obtain the food processing costs from GTAP v.7 database (GTAP sectors 21, 23-25), and normalize them by the total expenditures on other primary resources. To compute the normalized average cost of producing services from processed food, $c^{o, f}$, we divide normalized expenditures by the output of services from processed grains and crops produced in 2004 .

\section{B.1.3.2 Energy Services}

We obtain the initial values for total consumption of liquid fossil fuels and first generation biofuels from the BP Statistical Review of World Energy database (2013). The elasticity of substitution of fossil fuels for first generation biofuels is based on Hertel et al. (2010) econometric estimates for the US biofuel industry over the 2001-2008 period. Energy efficiency index, and the value shares of

biofuels and fossil fuels in energy production in 2004 are calibrated as described in Rutherford (2002).

\section{B.1.3.3 Processed Timber}

We calculate the level of technology index of the timber processing sector in 2004 using GTAP v.7 data, by dividing the output of timber products (GTAP sectors 30-31) by the output of commercial forestry sector (GTAP sector 13). We obtain the timber processing costs from GTAP v.7 database (GTAP sectors 3031 ), and normalize them by the total expenditures on other primary resources. 
To compute the normalized average cost of producing services from processed timber, $c^{o, s}$, we divide normalized expenditures by the output of services from processed timber produced in 2004.

\section{B.1.3.4 Ecosystem Services}

The parameters for production of ecosystem services in production function A.20 are based on the estimates of Costanza et al. (1997), who estimated values for 17 ecosystem services from 16 ecosystem types at global scale. ${ }^{6}$ We exclude the services from the production of food and timber, as well as from based climate abatement, as those are determined endogenously in the model. We also exclude the production of ecosystem services from ecosystems not represented in the model (e.g., marine, grasslands and deserts). We use agroecological zone (AEZ) representation of GTAP land use database to differentiate between tropical and temperate/boreal forest land. Based on ecological literature (Ehrlich and Mooney 1983) we assume that there is a limited substitution between different land types in production of ecosystem services. Because effectiveness of protected land areas is very difficult to quantify (Chape et al. 2005), we set the parameter $\theta^{R}$ large enough to make sure new protected areas are established.

We measure the non-land costs of managing protected natural areas based on GTAP v.7 database as public expenditures on outdoor recreation services per hectare of protected land, ${ }^{7}$ and normalize them by the total expenditures on other primary resources. To compute the normalized average cost of producing ecosystem services, $c^{o, r}$, we divide normalized expenditures by the output of ecosystem services per hectare of protected land produced in 2004.

\section{B.1.3.5 Other Final Goods and Services}

The initial values for the production of other goods and services are based on the value of output at agents' prices from GTAP v.7 database. The production of other goods and services is obtained from GTAP v.7 sectors 9-12, 14-15, 18-20, $22,26-29,33-42,45,47-54$ and $56-57$. The value of the total factor productivity index in 2004 is calculated as the ratio of other final goods and services to other primary goods and services. We set total factor productivity growth rate using

\footnotetext{
${ }^{6}$ We are familiar with multiple criticisms of this approach National Research Council (2005, p. 188-189). However, there have been very few attempts to evaluate production of ecosystem services at global scale, and the work of Costanza et al. (1997) still remains most influential.

${ }^{7}$ Following Antoine et al. (2008), we define outdoor recreation services sector based on GTAP v.7 database. This sector comprises of hunting and fishing, wildlife viewing in reserves, and other wildlife viewing activities.
} 
Jorgenson and $\mathrm{Vu}$ (2010) projections based on econometric estimates for 122 economies over the 1990 - 2008 period (see Figure B.1, panel c).

\section{B.1.4 Population, Preferences, and Welfare}

\section{B.1.4.1 Population}

We assume that the population, $\Pi_{t}$, follows logistic (Verhulst) model with declining growth rates over time:

$$
\Pi_{t}=\frac{\Pi_{T} \Pi_{0} e^{\pi t}}{\Pi_{T}+\Pi_{0}\left(e^{\pi t}-1\right)},
$$

where $\Pi_{0}$ is level of population in 2004, $\Pi_{T}$ is the limiting population in 2104, and $\pi$ is the population growth rate. Compared to standard exponential growth assumption the logistic model provides a better fit to demographic projections, and has been recently adapted in the economic literature (Guerrini 2006, Bucci and Guerrini 2009, Guerrini 2010). Data on population in 2004 are from GTAP v.7 database. The estimate of limiting population is from United Nations Department of Economic and Social Affairs Population Division (2011). The logistic growth rate of population is calibrated to match United Nations Department of Economic and Social Affairs Population Division (2011) demographic projections (see Figure B.1, panel a).

\section{B.1.4.2 Preferences}

The parameters $\alpha_{q}, \beta_{q}$ and $\underline{y}^{q}$ defining the varying marginal budget shares of goods and services and the subsistence level of consumption $q$ in the consumers' total real expenditures in equation (A.30), are estimated by maximum likelihood based on the cross-section of 113 countries and regions listed in GTAP v.7 database as described in Cranfield et al. (2003) and Yu et al. (2004). The parameters $\alpha_{q}$ and $\beta_{q}$ were subsequently calibrated to match the allocation of

land resources in 2004, while keeping the key ratio $\frac{\alpha_{q}}{\beta_{q}}$ defining the income and price elasticities constant.

We assume that the coefficient of relative risk aversion parameter $\gamma$ is equal to 2 , the value that has been commonly used in the economic modeling of climate change (Weitzman 2010, Pindyck 2011). 


\section{B.1.4.3 Welfare}

We set the social discount rate to 5 percent, which has been previously used in the economic analysis of land use in agriculture and forestry (Plantinga 1996, Stavins 1999). We set the scrap value function to zero. We have tried other functional forms and found it has a small effect on allocation of global land use over the first hundred years, which are the focus of this study.

\section{C.1 Solution Algorithm}

This section presents the algorithm of parametric dynamic programming (DP) with value function iteration for finite horizon problems employed to solve the dynamic stochastic model. Detailed discussion of numerical DP can be found in Cai (2010), Judd (1998) and Rust (2008). In dynamic programming problems, when the value function is continuous, it has to be approximated. We use a finitely parametrized collection of functions to approximate a value function, $V(x, \theta) \approx \hat{V}(x, \theta ; \mathbf{b})$, where $x$ is the continuous state vector (in this study, it is the $\left(v_{\max }+4\right)$ dimensional vector, $\left(L^{N}, L^{A}, L^{R}, L^{C}, X^{F}\right)$, and $\theta=\theta^{c}$ is the discrete state) and $\mathbf{b}$ is a vector of parameters. The functional form $\hat{V}$ may be a linear combination of polynomials, or it may represent a rational function or neural network representation, or it may be some other parametrization especially designed for the problem. After the functional form is fixed, we focus on finding the vector of parameters, $\mathbf{b}$, such that $\hat{V}(x, \theta ; \mathbf{b})$ approximately satisfies the Bellman equation, which can be written in a general form:

$$
\begin{gathered}
V_{t}(x, \theta)=\max _{a \in \mathcal{D}(x, t)} U_{t}(x, a)+\delta \mathbb{E}\left\{V_{t+1}\left(x^{+}, \theta^{+}\right)\right\}, \\
\text {s.t. } x^{+}=f(x, a, \omega),
\end{gathered}
$$

where $V_{t}(x, \theta)$ is the value function at time $t \leq T$ (the terminal value function $V_{T}(x, \theta)$ is given), $a$ is the action variable vector (in this study, it includes $\Delta^{N, A}, \Delta^{N, R}, \Delta^{C, A}, \Delta^{C, H}, \Delta^{C, C}, \Delta_{t}^{F, E}, \Delta_{t}^{F, n}, \vec{y}$, etc. $), x^{+}$is the next-stage state vector $\left(L_{t+1}^{N}, L_{t+1}^{A}, L_{t+1}^{R}, L_{t+1}^{C}, X_{t+1}^{F}\right), \mathcal{D}(x, t)$ is a feasible set of $a, \omega$ is a random variable, $\delta$ is a discount factor and $U_{t}(x, a)$ is the payoff function at time $t$. 
$\overline{\text { Algorithm } 1 \text { Value Function Iteration for the General Dynamic Programming }}$ Model

Initialization. Choose the approximation nodes, $\mathbb{X}_{t}=\left\{x_{i, t}: 1 \leq i \leq N_{t}\right\}$ for every $t<T$, and choose a functional form for $\hat{V}(x, \theta ; \mathbf{b})$ for every discrete state $\theta \in \Theta$. Let $\hat{V}\left(x, \theta ; \mathbf{b}^{T}\right)=V_{T}(x, \theta)$. Then for $t=T-1, T-2, \ldots, 0$, iterate through steps 1 and 2.

Step 1. Maximization step. For each $\theta_{j} \in \Theta$, compute

$$
v_{i, j}=\max _{a \in \mathcal{D}\left(x_{i}, t\right)} U_{t}\left(x_{i}, a\right)+\beta \mathbb{E}\left\{\hat{V}\left(x^{+}, \theta^{+} ; \mathbf{b}^{t+1}\right)\right\}
$$

for each $x_{i} \in \mathbb{X}_{t}, 1 \leq i \leq N_{t}$, where $\left(x^{+}, \theta^{+}\right)$is the next-stage state transited from $\left(x_{i}, \theta_{j}\right)$.

Step 2. Fitting step. Using an appropriate approximation method, compute $\mathbf{b}^{t}$, such that $\hat{V}\left(x, \theta_{j} ; \mathbf{b}^{t}\right)$ approximates $\left\{\left(x_{i}, v_{i, j}\right): 1 \leq i \leq N_{t}\right\}$ data, i.e., $v_{i, j} \approx \hat{V}\left(x_{i}, \theta_{j} ; \mathbf{b}^{t}\right)$ for all $x_{i} \in \mathbb{X}_{t}$ and $\theta_{j} \in \Theta$.

Algorithm 1 includes three types of numerical problems. First, we need to solve a maximization problem at each node $x_{i} \in \mathbb{X}_{t}$. Second, the evaluation of the objective requires us to compute an expectation. Third, we need to efficiently take the data and compute the best fit for the new value function. The challenge is not only to use good numerical methods for each of these steps but also to choose methods that are compatible with each other and jointly lead to efficient algorithms. Our code is written in FORTRAN and uses the methods presented in Cai (2010), Cai and Judd (2010, 2014), Cai et al. (2013) and we use NPSOL Gill et al. (1998) as the optimization solver in the maximization step. 


\section{D.1 Supplementary Figures}

a)
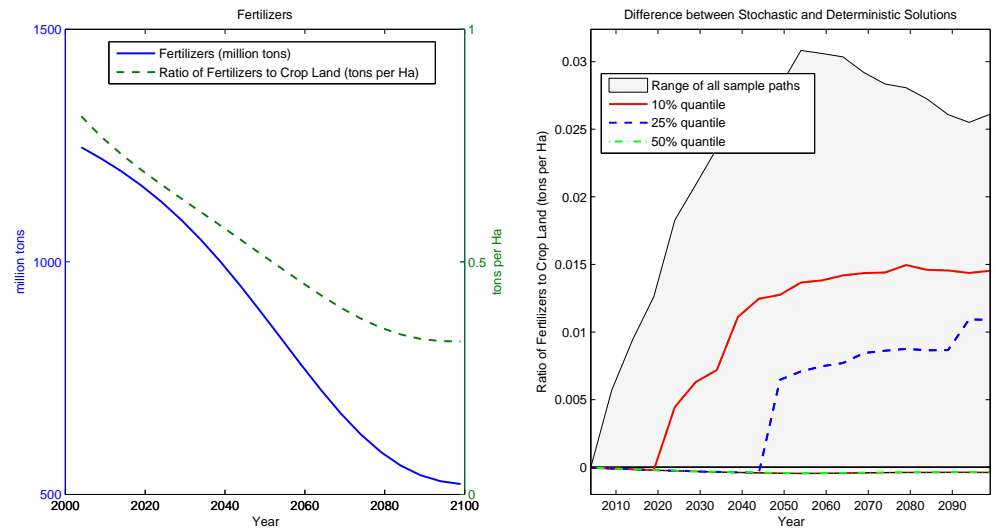

b)
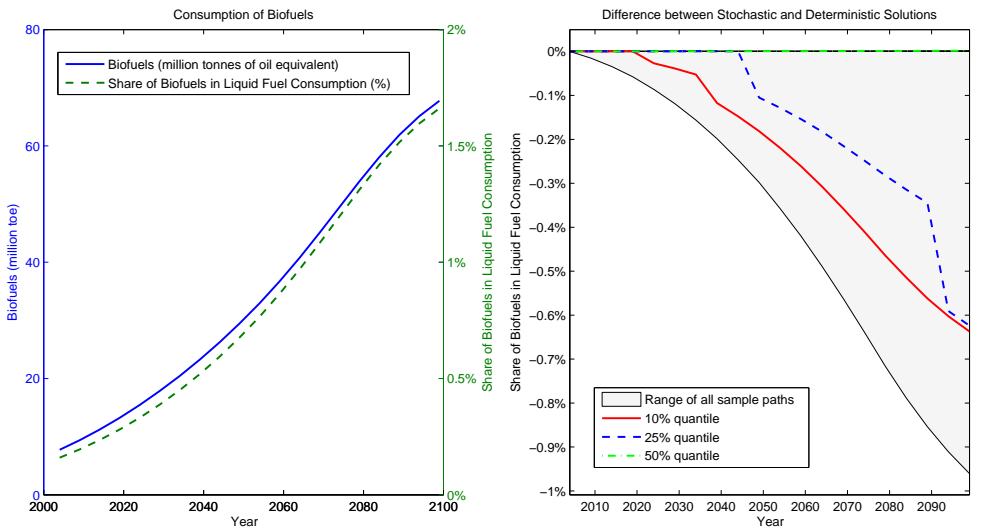

Figure D.1: Consumption of Fertilizers and Biofuels under Climate and Technology Uncertainty

\section{References}

Antoine, B., Gurgel, A. and Reilly, J.: 2008, Will Recreation Demand for Land Limit Biofuels Production?, Journal of Agricultural E Food Industrial Organization 6(2), 5 .

Brazee, R. and Mendelsohn, R.: 1990, A Dynamic Model of Timber Markets, Forest Science 36(2), 255-264. 
Bucci, A. and Guerrini, L.: 2009, Transitional Dynamics in the Solow-Swan Growth Model with AK Technology and Logistic Population Change, The BE Journal of Macroeconomics $\mathbf{9}(1), 43$.

Cai, Y.: 2010, Dynamic Programming and its Application in Economics and Finance, $\mathrm{PhD}$ thesis, Stanford University.

Cai, Y. and Judd, K. L.: 2010, Stable and Efficient Computational Methods for Dynamic Programming, Journal of the European Economic Association $8(2-3), 626-634$.

Cai, Y. and Judd, K. L.: 2014, Advances in Numerical Dynamic Programming and New Applications, in K. L. Judd and K. Schmedders (eds), Handbook of Computational Economics, Elsevier.

Cai, Y., Judd, K. L., Thain, G. and Wright, S. J.: 2013, Solving Dynamic Programming Problems on a Computational Grid, Working Paper 18714, National Bureau of Economic Research.

Chape, S., Harrison, J., Spalding, M. and Lysenko, I.: 2005, Measuring the Extent and Effectiveness of Protected Areas as an Indicator for Meeting Global Biodiversity Targets, Philosophical Transactions of the Royal Society B: Biological Sciences 360(1454), 443-455.

Costanza, R., d'Arge, R., De Groot, R., Farber, S., Grasso, M., Hannon, B., Limburg, K., Naeem, S., O'Neill, R., Paruelo, J. et al.: 1997, The Value of the World's Ecosystem Services and Natural Capital, Nature 387(6630), 253-260.

Cranfield, J., Eales, J., Hertel, T. and Preckel, P.: 2003, Model Selection when Estimating and Predicting Consumer Demands using International, Cross Section Data, Empirical Economics 28(2), 353-364.

Cubbage, F., Koesbandana, S., Mac Donagh, P., Rubilar, R., Balmelli, G., Olmos, V., De La Torre, R., Murara, M., Hoeflich, V., Kotze, H. et al.: 2010, Global Timber Investments, Wood Costs, Regulation, and Risk, Biomass and Bioenergy 34(12), 1667-1678.

Ehrlich, P. and Mooney, H.: 1983, Extinction, Substitution, and Ecosystem Services, BioScience pp. 248-254.

FAO: 2010, Global Forest Resources Assessment 2010, FAO Forestry Paper 163, Food and Agriculture Organization of the United Nations. 
Gill, P., Murray, W., Saunders, M. and Wright, M.: 1998, Users Manual for NPSOL 5.0, A FORTRAN Package for Nonlinear Programming, Technical Report SOL 86-1, Department of Operations Research, Stanford University.

Guerrini, L.: 2006, The Solow-Swan Model with a Bounded Population Growth Rate, Journal of Mathematical Economics 42(1), 14-21.

Guerrini, L.: 2010, A Closed-form Solution to the Ramsey Model with Logistic Population Growth, Economic Modelling 27(5), 1178-1182.

Hartley, P., Medlock III, K. and Rosthal, J.: 2008, The Relationship of Natural Gas to Oil Prices, The Energy Journal 29(3), 47-66.

Hertel, T.: 1997, Global Trade Analysis: Modeling and Applications, Cambridge University Press.

Hertel, T., Rose, S. and Tol, R.: 2009, Economic Analysis of Land Use in Global Climate Change Policy, Routledge.

Hertel, T., Stiegert, K. and Vroomen, H.: 1996, Nitrogen-land Substitution in Corn Production: a Reconciliation of Aggregate and Firm-level Evidence, American Journal of Agricultural Economics 78(1), 30-40.

Hertel, T., Tyner, W. and Birur, D.: 2010, The Global Impacts of Biofuel Mandates, The Energy Journal 31(1), 75-100.

IPCC: 2000, Summary for Policymakers, in N. Nakićenović, J. Alcamo, G. Davis, B. De Vries, J. Fenhann, S. Gaffin, K. Gregory, A. Grübler, T. Jung, T. Kram et al. (eds), Special Report on Emissions Scenarios: A Special Report of Working Group III of the Intergovernmental Panel on Climate Change, Cambridge University Press.

Jorgenson, D. and Vu, K.: 2010, Potential Growth of the World Economy, Journal of Policy Modeling 32(5), 615-631.

Judd, K. L.: 1998, Numerical Methods in Economics, The MIT press.

Lee, H., Hertel, T., Rose, S. and Avetisyan, M.: 2009, An Integrated Global Land Use Data Base for CGE Analysis of Climate Policy Options, in T. Hertel, S. Rose and R. Tol (eds), Economic Analysis of Land Use in Global Climate Change Policy, Routledge, pp. 72-88. 
Narayanan, B. and Walmsley, T.: 2008, Global Trade, Assistance, and Production: The GTAP 7 Data Base, Center for Global Trade Analysis, Purdue University.

National Research Council: 2005, Valuing Ecosysten Services: Toward Better Eenvironmental Ddecision-Making, National Academies Press.

Nordhaus, W. D. and Boyer, J.: 2000, Warming the World: Economic Models of Global Warming, MIT press.

Pindyck, R. S.: 2011, Fat Tails, Thin Tails, and Climate Change Policy, Review of Environmental Economics and Policy 5(2), 258-274.

Plantinga, A. J.: 1996, The Effect of Agricultural Policies on Land Use and Environmental Quality, American Journal of Agricultural Economics 78(4), 10821091.

Rust, J.: 2008, Dynamic Programming, The New Palgrave Dictionary of Economics, London, UK, Palgrave Macmillan, Ltd.

Rutherford, T.: 2002, Lecture Notes on Constant Elasticity Functions, http: //www.gamsworld.org/mpsge/debreu/ces.pdf. [Online; accessed 14-April2011].

Sedjo, R.: 1983, The Comparative Economics of Plantation Forestry: A Global Assessment, Johns Hopkins University Press.

Sohngen, B., Golub, A. and Hertel, T.: 2009a, The Role of Forestry in Carbon Sequestration in General Equilibrium Models, in T. Hertel, S. Rose and R. Tol (eds), Economic Analysis of Land Use in Global Climate Change Policy, Routledge, pp. 279-303.

Sohngen, B. and Mendelsohn, R.: 2007, A Sensitivity Analysis of Forest Carbon Sequestration, in M. Schlesinger (ed.), Human-Induced Climate Change: An Interdisciplinary Assessment, Cambridge University Press, pp. 227-237.

Sohngen, B., Tennity, C., Hnytka, M. and Meeusen, K.: 2009b, Global Forestry Data for the Economic Modeling of Land Use, in T. Hertel, S. Rose and R. Tol (eds), Economic Analysis of Land Use in Global Climate Change Policy, Routledge, pp. 49-71.

Stavins, R.: 1999, The Costs of Carbon Sequestration: A Revealed-preference Approach, The American Economic Review 89(4), 994-1009. 
Taheripour, F. and Tyner, W.: 2011, Introducing First and Second Generation Biofuels into GTAP Data Base Version 7, GTAP Research Memorandum 21, Center for Global Trade Analysis, Purdue University.

United Nations Department of Economic and Social Affairs Population Division: 2011, World Population Prospects: The 2010 Revision, http://esa.un .org/ unpd/wpp/index.htm. [Online; accessed 10-June-2011].

USGAO: 2003, Natural Gas: Domestic Nitrogen Fertilizer Production Depends on Natural Gas Availability and Prices, Report to the Ranking Democratic Member, Committee on Agriculture, Nutrition and Forestry, U.S. Senate GAO-03-1148, United States General Accounting Office.

Weitzman, M. L.: 2010, What Is The "Damages Function" For Global Warming - And What Difference Might It Make?, Climate Change Economics 1(01), 5769.

Winston, A.: 2009, Enhancing Agriculture and Energy Sector Analysis in CGE Modelling: An Overview of Modifications to the USAGE Model, Centre of Policy Studies/IMPACT Centre Working Paper G-108, Monash University, Centre of Policy Studies/IMPACT Centre.

Yu, W., Hertel, T., Preckel, P. and Eales, J.: 2004, Projecting World Food Demand Using Alternative Demand Systems, Economic Modelling 21(1), 99129. 